\title{
Trichoderma harzianum-Mediated ZnO Nanoparticles: A Green Tool for Controlling Soil-Borne Pathogens in Cotton
}

\author{
Shimaa A. Zaki ${ }^{1,2}$, Salama A. Ouf ${ }^{1}$, Fawziah M. Albarakaty ${ }^{3, *}$, Marian M. Habeb ${ }^{2}$, Aly A. Aly ${ }^{2}$ \\ and Kamel A. Abd-Elsalam 2,*(D) \\ 1 Botany and Microbiology Department, Faculty of Science, Cairo University, Giza 12613, Egypt; \\ shim.shimshim@yahoo.com (S.A.Z.); salama@sci.cu.edu.eg (S.A.O.) \\ 2 Plant Pathology Research Institute, Agricultural Research Centre, Giza 12619, Egypt; \\ marianmonir12@gmail.com (M.M.H.); aly.a.a@post.com (A.A.A.) \\ 3 Department of Biology, Faculty of Applied Science, Umm Al-Qura University, \\ Makkah Al Mukarramah P.O. Box 715, Saudi Arabia \\ * Correspondence: fmbarakati@uqu.edu.sa (F.M.A.); kamelabdelsalam@gmail.com (K.A.A.-E.)
}

Citation: Zaki, S.A.; Ouf, S.A.; Albarakaty, F.M.; Habeb, M.M.; Aly, A.A.; Abd-Elsalam, K.A. Trichoderma harzianum-Mediated $\mathrm{ZnO}$ Nanoparticles: A Green Tool for Controlling Soil-Borne Pathogens in Cotton. J. Fungi 2021, 7, 952. https:// doi.org/10.3390/jof7110952

Academic Editor: Nuria Ferrol

Received: 27 September 2021

Accepted: 25 October 2021

Published: 10 November 2021

Publisher's Note: MDPI stays neutral with regard to jurisdictional claims in published maps and institutional affiliations.

Copyright: (c) 2021 by the authors. Licensee MDPI, Basel, Switzerland. This article is an open access article distributed under the terms and conditions of the Creative Commons Attribution (CC BY) license (https:/ / creativecommons.org/licenses/by/ $4.0 /)$.

\begin{abstract}
ZnO-based nanomaterials have high antifungal effects, such as inhibition of growth and reproduction of some pathogenic fungi, such as Fusarium sp., Rhizoctonia solani and Macrophomina phaseolina. Therefore, we report the extracellular synthesis of ZnONPs using a potential fungal antagonist (Trichoderma harzianum). ZnONPs were then characterized for their size, shape, charge and composition by visual analysis, UV-visible spectrometry, X-ray diffraction (XRD), Zeta potential, transmission electron microscopy (TEM), scanning electron microscopy (SEM) and energy-dispersive X-ray analysis (EDX). The TEM test confirmed that the size of the produced ZnONPs was 8-23 nm. The green synthesized ZnONPs were characterized by Fourier transform infrared spectroscopy (FTIR) studies to reveal the functional group attributed to the formation of ZnONPs. For the first time, trichogenic ZnONPs were shown to have fungicidal action against three soil-cotton pathogenic fungi in the laboratory and greenhouse. An antifungal examination was used to evaluate the bioactivity of the mycogenic ZnONPs in addition to two chemical fungicides (Moncut and Maxim XL) against three soil-borne pathogens, including Fusarium sp., Rhizoctonia solani and Macrophomina phaseolina. The findings of this study show a novel fungicidal activity in in vitro assay for complete inhibition of fungal growth of tested plant pathogenic fungi, as well as a considerable reduction in cotton seedling disease symptoms under greenhouse conditions. The formulation of a trichogenic ZnONPs form was found to increase its antifungal effect significantly. Finally, the utilization of biocontrol agents, such as T. harzianum, could be a safe strategy for the synthesis of a medium-scale of ZnONPs and employ it for fungal disease control in cotton.
\end{abstract}

Keywords: zinc oxide nanoparticles; Gossypium barbadense; Fusarium sp.; Rhizoctonia solani; Macrophomina phaseolina

\section{Introduction}

Cotton (Gossypium barbadense L.) is a globally important crop that is extensively produced and traded, as well as one of Egypt's most valuable export crops [1]. Diseases of cotton seedlings are a worldwide problem caused by pathogenic soil-borne fungi. Fusarium spp. and Rhizoctonia solani are among the most pathogenic fungi present in cottonproducing regions in Egypt [2]. R. solani Kuhn, an anamorph of Thanatephorus cucumeris (Frank.) Donk [3], can cause pre-or post-emergence damping-off, seedling blight and root rot in cotton seedlings. Fusarium spp. are frequently obtained from infected cotton roots and classified as cotton seedling root pathogens [4]. M. phaseolina (Tassi) Goid infects over 100 families and 500 plant species all over the world [5,6]. M. phaseolina can cause charcoal rot in an abroad range of crops, such as sorghum, soybean, cotton, bean and corn, when conditions are favorable [7]. 
Bio-based NP synthesis has received a lot of interest in the last five years. It has eliminated difficult procedures necessary for NPs production utilizing microorganisms, such as fungi, bacteria and yeast, such as microbial cell culture upkeep, prolonged incubation time, several purification steps and so on [8]. Mycogenic nanoparticles offer advantages, including the formation of a capping from fungal biomolecules, which provides stability and can contribute to various biological activities [9]. ZnONPs were synthesized from fungal secondary metabolites of three monocultures of Trichoderma species including, T. harzianum and T. reesei. ZnONPs were biogenically produced using a cell filtrate of a strain of T. harzianum as a reducer and stabilizer agent [10]. Nevertheless, the microbial synthesis of ZnNPs remains unexplored [11]. Monoascus purpureus-mediated zinc oxide nanoparticles showed potent antifungal activity against six species of the most common food spoilage fungi [12].

Sustainable nanomaterials have become a promising option to control plant pathogenic fungi that are responsible for diseases in different crops. Crops treated with safe nanofungicides will acquire additional value because they are free of chemicals and effective at low doses [9]. They reduce food and feed spoilage and fungal pathogens and help protect human health and sustain the universal demand for high product quality $[13,14]$. Because of the broad range of uses of zinc oxide nanoparticles (ZnONPs), such as smart UV sensors, they have piqued researchers' attention [15], targeted drug delivery [16], antioxidant activity [17] biosensors [18], environmental remediation [19] and as a drought-tolerant agent as well as nutrient supply of crops [20]. Moreover, ZnONPs are characterized to be efficient against pathogenic fungi, mostly by their antimicrobial properties according to their photo-oxidizing and photocatalytic effects and considering infection control for the plant host [21]. Recently detailed reviews introduced the preparation methods and antifungal properties of ZnONPs and their possible antifungal mechanisms for plant diseases management and to improve food quality $[22,23]$. Under in vitro conditions, the biosynthesis of ZnONPs produced from Trichodermas spp. was used to suppress the development of Xanthomonas oryzae pv. oryzae [10]. An interactive protective impact of ZnONPs on seedling spray/seed soak followed by seedling and biocontrol treatments, $T$. harzianum, enhanced plant resistance to $R$. solani, the causal organisms of sunflower seedlings damping-off [24].

Antibacterial, antifungal, antiviral and anti-toxigenic activities against a range of phytopathogens may be achieved using zinc-based nanomaterials, which have targeted antimicrobial capabilities and low to negligible phytotoxic activities (Khan et al., 2021) [25]. Several applications methods may be used to employ these formulations in open fields or under greenhouse environments [22-24]. The use of fungi in the biogenic synthesis of $\mathrm{ZnONPs}$ has several benefits, including the production of a capping from fungal biomolecules, which provides stability and can contribute to different biological activities, such as the development of safe nanofungicides. Limited reports have used a T. harzianum cell filtrate for the production of ZnONPs as only a reducer and stabilizer agent [26]. Therefore, the main aims of the present study were to (1) synthesis a novel trichogenic-ZnONPs using an easy, eco-friendly, environmentally safe and costless approach, employing fungal metabolites from $T$. harzianum strains as a reducing agent and stabilizer to synthesize ZnONPs; (2) characterize the synthesized ZnONPs to confirm synthesis, structure, size and NPs morphology; (3) investigate the in vitro and in vivo antifungal activity of mycogenic ZnONPs against soil-borne pathogenic fungi including R. solani, Fusarium sp. and $M$. phaseolina isolated from infected soil in cotton-growing areas.

\section{Materials and Methods}

\subsection{Preparation of Trichoderma Isolates Culture}

Trichoderma sp. isolates were isolated from healthy cotton root rhizosphere soils. Various soil dilutions were cultivated on Rose Bengal Medium (Sigma-Aldrich, St. Louis, $\mathrm{MO}$, USA) [27]. After $48 \mathrm{~h}$, Trichoderma colonies were collected and cultivated on potato dextrose agar (PDA) (Sigma-Aldrich, St., Louis, MO, USA) media. Single spore isolation 
was used to isolate putative Trichoderma colonies [28]. To obtain a pure isolate, a single spore was transferred to a PDA medium. Trichoderma species were identified based on morphology technique in Assiut University Mycology Center (AUMC), Assuit, Egypt.

\subsection{Preparation of Cultural Extract}

The fungi were allowed to grow aerobically in a liquid medium containing $\mathrm{KH}_{2} \mathrm{PO}_{4}$ $(7 \mathrm{~g} / \mathrm{L}) ; \mathrm{K}_{2} \mathrm{HPO}_{4}(2 \mathrm{~g} / \mathrm{L}) ; \mathrm{MgSO}_{4} \cdot 7 \mathrm{H}_{2} \mathrm{O}(0.1 \mathrm{~g} / \mathrm{L}) ;\left(\mathrm{NH}_{2}\right) \mathrm{SO}_{4}(1 \mathrm{~g} / \mathrm{L}) ; y$ east extract $(0.6 \mathrm{~g} / \mathrm{L}) ;$ glucose $(10 \mathrm{~g} / \mathrm{L})$, to prepare the biomass for biosynthesis experiments. The growing cultures were incubated in an orbital shaker and agitated at $150 \mathrm{rpm}$ at $27^{\circ} \mathrm{C}$. The produced biomass was collected by sieving through a plastic sieve after $72 \mathrm{~h}$ of growth. After that, the biomass was thoroughly washed with sterile distilled water to remove any remaining broth medium components. At $28^{\circ} \mathrm{C}$ for $48 \mathrm{~h}$, Trichoderma biomass $(20 \mathrm{~g})$ was transferred to an Erlenmeyer flask containing $100 \mathrm{~mL}$ sterile deionized water. The biomass was agitated after incubation and the filtrate was obtained by filtering it using Whatman (Sigma-Aldrich, St., Louis, MO, USA) filter paper \#1 [29].

\subsection{Synthesis of Zinc Oxide Nanoparticles}

Fifty millilitres $\mathrm{Zn}\left(\mathrm{CH}_{3} \mathrm{COO}\right)_{2} \cdot 2 \mathrm{H}_{2} \mathrm{O}$ salt (Molecular Biology Grade, Merck, Kenilworth, NJ, USA) was applied to $50 \mathrm{~mL}$ fungal filtrate and incubated for $72 \mathrm{~h}$ at $150 \mathrm{rpm}$ in an orbital shaker. A fungal biomass filtrate without the zinc acetate dihydrate solution served as a positive control, while the zinc acetate dihydrate with cell-free filtrate served as a negative control. After centrifugation at 10,000 rpm for $10 \mathrm{~min}$, the pellet aggregated at the bottom of the flask was removed from the filtrate and lyophilized [30]. ZnONPs were dried overnight at $60^{\circ} \mathrm{C}$ in an oven and used for further research to evaluate fungicidal activity. For NPs characterization, the developed ZnONPs were subjected to a variety of instrumental analytical techniques to describe physico-chemical proporties.

\subsection{Characterization of Nanoparticles}

\subsubsection{Ultraviolet-Visible Spectrophotometer Analysis}

A UV-vis spectrophotometer (T80 UV/vis spectrophotometer, PG Instruments Limited, Lutterworth, UK) was used to test the formation of reduced nanoparticles in colloidal solution. The supernatants' absorption spectra were measured between 200 and $800 \mathrm{~nm}$. The formation of ZnONPs was detected by periodic sampling of aliquots $(1 \mathrm{~mL})$ of the aqueous portion in the range of 0 to $1100 \mathrm{~nm}$ using an ultraviolet-visible spectrophotometer after 2, 4 and 7 days. Distilled water was used as a blank.

\subsubsection{Transmission Electron Microscopy (TEM)}

Powder samples were put into a mortar before being mounted on a 200-mesh copper specimen grid with a film coating. At an accelerating voltage of $80 \mathrm{kV}$, TEM micrographs were taken on a Carl Zeiss Leo 912 AB OMEGA electron microscope (Carl Zeiss AG, Jena, Germany). After a drop of liquid ZnONPs was dried on the carbon-coated copper grids, a sample for analysis was prepared. Until loading onto a specimen holder, desiccators were used to dry TEM grid samples and keep them under vacuum. Image J $1.45 \mathrm{~s}$ software was used to assess the particle size distribution of nanoparticles.

\subsubsection{Zeta Potential}

A sample was prepared by dissolving ZnONPs powder in deionized water, then the sample was sonicated for $10 \mathrm{~min}$ using the Q500 sonicator. The zeta potential of an aqueous solution of ZnONPs was measured in Folded Capillary cell (DTS1070) with pH ranging from 2 to 11 by applying $\pm 65 \mathrm{~V}$ across the electrodes by Zetatrac equipped with Mic rotrac FLEX Operating Software on Mansettingnano (Malvern Instruments, South borough, MA, USA). 


\subsubsection{X-ray Diffraction (XRD)}

$\mathrm{X}$-ray Diffraction (XRD) analysis was used to examine the structure of powder nanoparticles. $\mathrm{Cu} \mathrm{K} \alpha$ radiation $(\lambda=1.54 \AA)$ was used in the scattering range $(2 \theta)$ of 0 to $80^{\circ}$ at a scan rate of $0.03 S 1$ on a D8-A25-Advance diffractometer (Bruker, Karlsruhe, Germany). As an internal standard for calibration, a standard silicon sample was used.

\subsubsection{Scanning Electron Microscope (SEM)}

Scanning electron microscopical analysis was made using a Tescan SEM (Tescanvega 3 SBU, Czech Republic) at an accelerating voltage of $20 \mathrm{kV}$. Samples were mounted on aluminium microscopy stubs using carbon tape, then coated with gold ( $\mathrm{Au}$ ) for $120 \mathrm{~s}$ using a Quorum Techniques Ltd. sputter coater (Q150t, Lewes, UK).

\subsubsection{Energy Dispersive X-ray (EDX) Spectroscopy}

On a JEOL(JEM-1230) electron microscope (Jeol, Tokyo, Japan), a drop of ZnONPs was put on carbon-coated copper grids and allowed to sit for $2 \mathrm{~min}$ and the excess solution was extracted with blotting paper and allowed to dry at room temperature.

\subsubsection{Fourier TransformInfrared Spectroscopy (FTIR)}

FTIR spectra were performed on a JASCO-4700 FTIR Spectrometer (Laser Spectroscopy Labs, UCI, Irvine, CA, USA) to detect the possible functional groups in biomolecules present in the fungal extract.

\subsection{In Vitro Antifungal Activity of Synthesized Nanoparticles}

To evaluate the antifungal effect of nanoparticles in vitro, R. solani (Rs9), Fusarium sp. (F10) and M. phaseolina isolate (M4) were grown in PDA medium at $35^{\circ} \mathrm{C}$ for 7 days. Then, freshly prepared PDA containing different concentrations of synthesized ZnONPs (20, 40 and $100 \mu \mathrm{g} / \mathrm{mL}$ ) were added. ZnONPs solutions were put in an ultrasonic bath for $15 \mathrm{~min}$ at a sonicating frequency of $37 \mathrm{kHz}$ (Elmasonic S60, Elma, Singen, Germany) to disrupt nanoparticle aggregations. After the fungal media cooled to about $45^{\circ} \mathrm{C}$, the sonicated NPs were inoculated into the media, then the fungal culture medium was poured into Petri dishes. Five-millimetre disks of fungal inoculum were cut with a cork borer and inoculated at the center of the 9 -cm-diameter Petri dish, incubated at $35^{\circ} \mathrm{C}$ for $5-7$ days. PDA plates free from $\mathrm{ZnONPs}$ cultured under the same conditions were used as controls. The linear growth of the fungi was measured [31].

\subsection{Antifungal Activity under Greenhouse Conditions}

In a greenhouse experiment, the effects of synthesized ZnONPs were evaluated against $R$. solani (RS9), Fusarium sp. (F10) and M. phaseolina (M4) on cotton cultivars Giza90 and Giza94. The pots, containing the autoclaved soil, were infested with two-week-old pathogen-sorghum cultures of R. solani (RS9), Fusarium sp. (F10) and M. phaseolina (M4) at a rate of 1,5 and $50 \mathrm{~g} / \mathrm{kg}$ soil, respectively. Cotton cultivars Giza90 and Giza94 seeds were surfaces sterilized with $10 \%$ sodium hypochlorite for $2 \mathrm{~min}$ before being washed in four changes of sterilized water. The sterilized seeds were subsequently immersed in a suspension of $\mathrm{ZnONPs}$ at 100 and $200 \mu \mathrm{g} / \mathrm{mL}$ concentrations for $12 \mathrm{~h}$ under static circumstances. The tested fungicides (Moncut $(2 \mathrm{~g} / \mathrm{kg}$ seeds) and Maxim XL $(2 \mathrm{~mL} / \mathrm{L})$ ) were added to slightly moist seeds of cotton cultivars Giza90 and Giza94. Table 1. Infested soil was poured into $15-\mathrm{cm}$ pots, with 10 seeds sown in each pot. Sterilized sorghum grains were mixed fully with soil cotton seeds only in the control treatments. In infested control, infested soil at the rate of $1 \mathrm{~g} / \mathrm{kg}$ of soil R. solani (RS9) and $50 \mathrm{~g} / \mathrm{kg}$ of soil for Fusarium sp. (F10) and M. phaseolina (M4) with cotton seeds without any treatment was applied. At $28{ }^{\circ} \mathrm{C}$, pots were dispersed on greenhouse benches randomly in a complete block design. There were three replicates (pots) for each treatment. Forty-five days after planting, plant height (cm/plant), dry weight ( $\mathrm{g} / \mathrm{plant})$ and survival percentages were all measured [32]. 
Table 1. Fungicides and Trichogenic-ZnONPs applied in controlling damping-off of cotton seedlings under greenhouse conditions.

\begin{tabular}{|c|c|c|c|}
\hline Treatment & $\begin{array}{l}\text { Application } \\
\text { Methods }\end{array}$ & Active Ingredients & Rate of Application \\
\hline 1-autoclaved soil & Seed dressing & Untreated & $\begin{array}{c}1 \mathrm{~g} \text { for R. solani and } 50 \mathrm{~g} \text { for Fusaruim and M. phaseolina } \\
\text { sterilized sorghum } / \mathrm{kg} \text { soil }\end{array}$ \\
\hline 2-infested soil & Seed dressing & Untreated & $\begin{array}{c}1 \mathrm{~g} \text { for R. solani and } 50 \mathrm{~g} \text { for Fusaruim and M. phaseolina } \\
\text { infested sorghum } / \mathrm{kg} \text { soil }\end{array}$ \\
\hline 3-Moncut & Seed dressing & Flutolanil & $2 \mathrm{~g} / \mathrm{kg}$ seeds \\
\hline 4-Maxim XL & Seed dressing & Fludioxonil, Mefanoxam & $2 \mathrm{~mL} / \mathrm{L}$ \\
\hline 5-ZnONPs & Seed dressing & Zinc Oxide & $100 \mu \mathrm{g} / \mathrm{mL}$ \\
\hline 6-ZnONPs & Seed dressing & Zinc Oxide & $200 \mu \mathrm{g} / \mathrm{mL}$ \\
\hline
\end{tabular}

\subsection{Statistical Analysis}

Data were subjected to statistical analysis of variance (ANOVA) via MSTAT-C software. The mean differences were compared by the least significant difference (LSD) test at $p \leq 0.05$.

\section{Results}

\subsection{Trichoderma Isolates}

A total of 50 Trichoderma strains (TC1-T50) were obtained from 22 soil samples. On the PDA medium, the colony's growth speed, conidiospore color, wheel pattern and pigment secretion were all studied. Then, they were identified by morphological methods, which identified 6 Trichoderma species.

\subsection{Trichogenic Nanoparticles Synthesis}

The synthesis of ZnONPs was detected by UV-vis and from all the strains screened, only four had the aptitude to synthesize ZnONPs. Three Trichoderma species (Tvivi, TC34 and TC28) were used for the biosynthesis of stable ZnONPs. Filtrates from each fungal strain were incubated with zinc acetate dihydrate for $72 \mathrm{~h}$ under dark conditions at $28^{\circ} \mathrm{C}$ with agitation.

\subsection{Physiochemical Characterization}

\subsubsection{UV-Vis Spectrophotometer}

Figure 1 shows the UV-vis absorption spectrum of zinc oxide nanoparticles. The absorption spectrum was recorded for the synthesized ZnONPs sample by Tvivi, TC 34 and TC 28 after 2, 4 and 7 days after synthesis in the range of 0 to $1100 \mathrm{~nm}$. The absorbance peak at $300 \mathrm{~nm}$, which corresponded to the distinctive band of ZnONPs, was visible in the spectrum, for all tested Trichoderma isolates at all tested days (Figure 1). ZnONPs produced by Tvivi strain was chosen for further characterization.

\subsubsection{Zeta Potential Analysis}

The surface charges gained by ZnONPs were detected using zeta potential analysis, which may be used to learn more about the stability of the colloidal ZnONPs.In the present assay, we used a concentration of $40 \mu \mathrm{g} / \mathrm{mL}$ to measure zeta potential. As a result of this propensity, certain nanoparticles tended to agglomerate, reducing their surface area. ZnONPs must undergo prolonged ultrasonication in a water bath for at least $15 \mathrm{~min}$ to fix this problem. The result also signifies the presence of repulsive electrostatic forces among the synthesized ZnONPs, which leads to the monodispersity of the particles. In the present study, the zeta potential of $\mathrm{ZnONPs}$ was measured and was recorded as $-24.0 \mathrm{mV}$ (Figure 2A). 

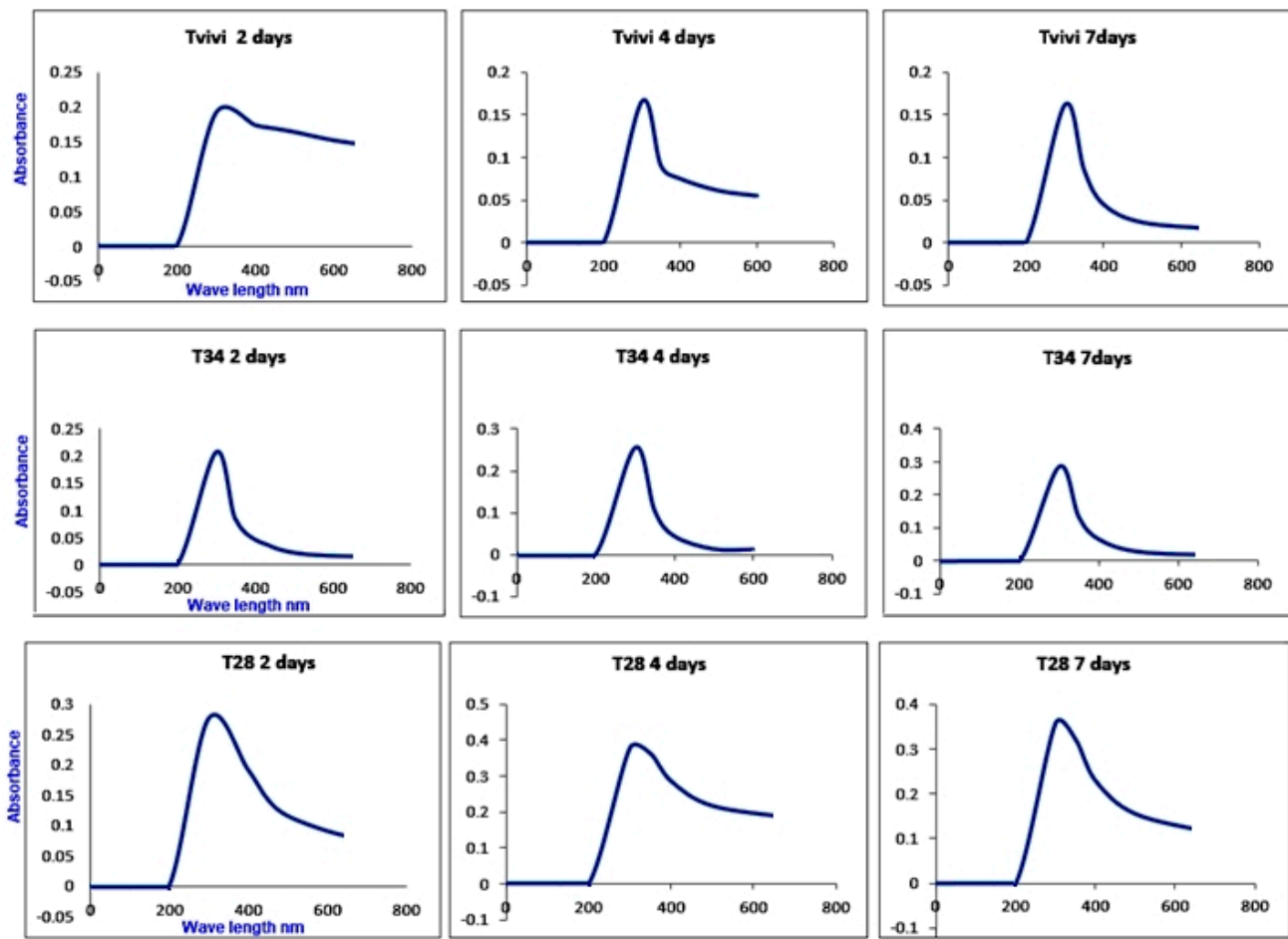

Figure 1. UV_vis spectrum of Trichogenic ZnONPs produced by Tvivi, T34 and T28 after 2, 4 and 7 days after synthesis.
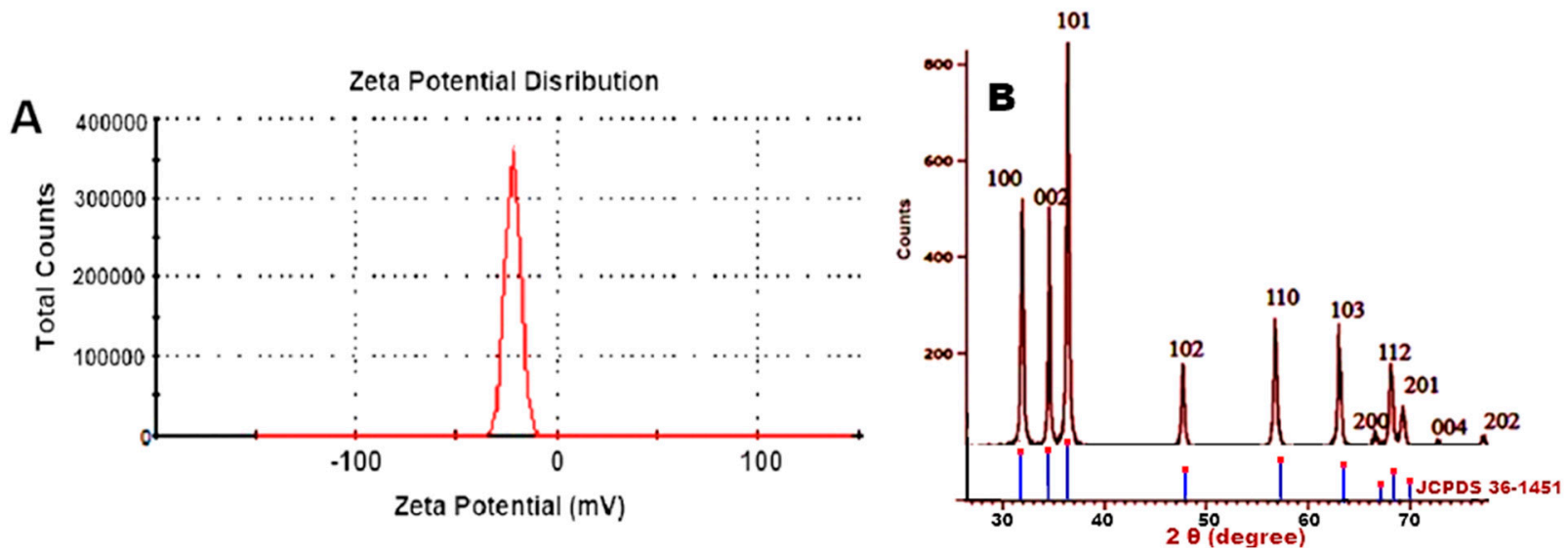

Figure 2. (A) Zeta potential analysis of synthesized ZnONPs. Trichoderma-mediated ZnONPs were spherical and rodshaped and the potential value was found to be $-24.0 \mathrm{mV}$. (B) X-ray diffraction pattern of Trichogenic ZnONPs. All peaks reveal the purity and crystalline nature. No traces of other impurity phases were detected.

\subsubsection{X-ray Powder Diffractometer (XRD)}

The XRD pattern of synthesized ZnONPs gave the diffraction peaks at (100), (002), (101), (102), (110), (103), (200), (112), (201), (004) and (202) planes, respectively, with the highest peak being the (101) plane (Figure 2B). The observed XRD peaks in the X-ray diffraction patterns of the $\mathrm{ZnO}$ samples were categorized by the hexagonal wurtzite structure of ZnO (JCPDS card 36-1451 data).

\subsubsection{Transmission Electron Microscopy (TEM)}

TEM was applied to know the actual size and shape of ZnONPs. The TEM image in the present study showed a mixture of hexagonal, spherical and rod-shaped a very small particles with a crystalline structure for the ZnONPs with an average size of 8-25 nm 
(Figure 3A). The ZnONPs were individuals and agglomerated in clusters. Diffraction rings could be allocated as (100), (002) and (101) planes from the selected area diffraction (SAED) pattern of ZnONPs (Figure 3B), representing hexagonal structure coupled with the wurtzite-like structure of ZnONPs as shown in the XRD pattern.
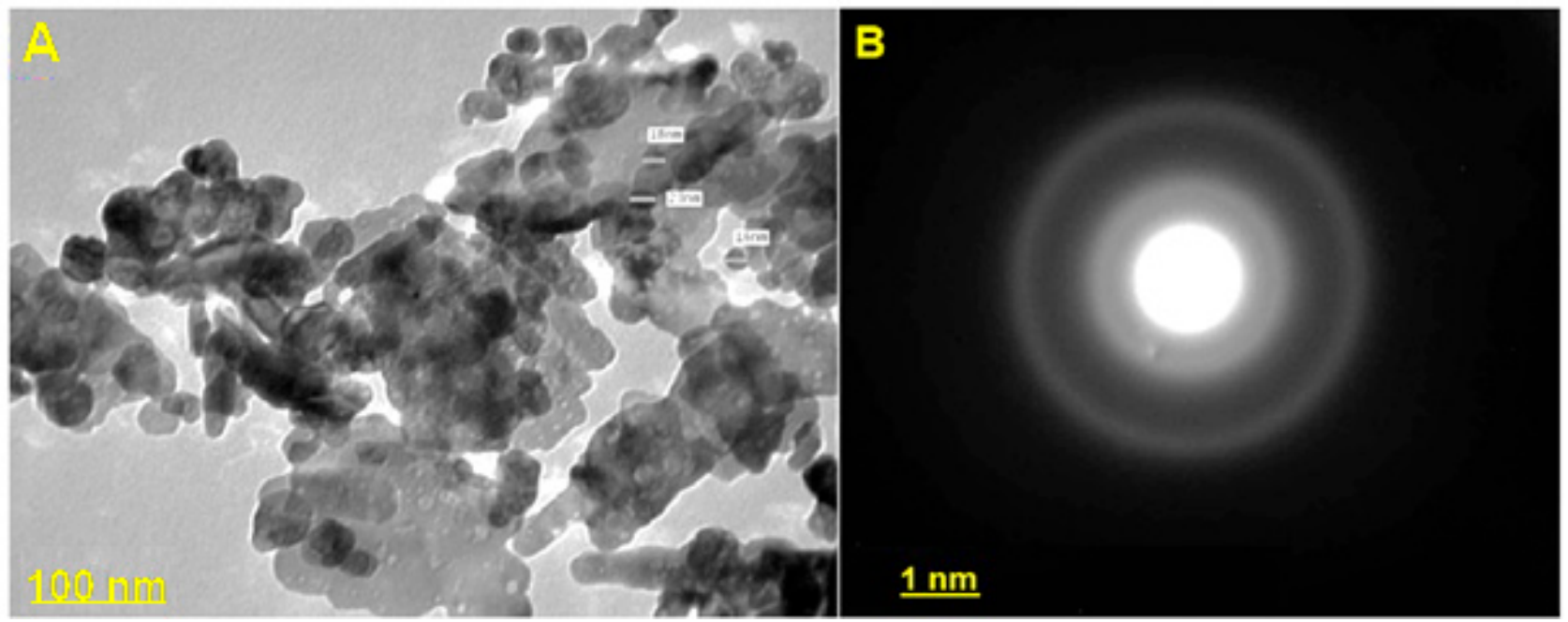

Figure 3. (A) Transmission electron microscopy (TEM) image of synthesized ZnO-NPs; the inset shows the corresponding particle size distribution and shape. (B): Selected Area Electron Diffraction (SAED) of Trichogenic-ZnONPs.

\subsubsection{Scanning Electron Microscopy (SEM)}

SEM is a high-resolution surface imaging approach that uses an electron beam to obtain information on nanostructures and other materials at the microscopic level. SEM analysis of synthesized ZnONPs exhibited clear spherical, rod and hexagonal shapes with and well-distributed ZnONPs with aggregation. Figure 4 presents a microscopic image of the obtained ZnONPs shown at different magnifications. The studies of the nanomaterial showed different sizes of the particles in a range comprising 24 to $50 \mathrm{~nm}$. The microstructure of nanocrystalline $\mathrm{ZnO}$ had a skeletal form resulting from the process of coagulation (Figure 4A,B). The ZnONPs (Figure 4C,D).

\subsubsection{Energy Dispersive X-ray Analysis (EDX)}

An EDX spectrum was used on the ZnONPs to determine the amount of metal and oxides in the sample. The EDX spectrum of the produced NPs was recorded in the spotprofile mode from one of the densely populated ZnONPs areas, as shown in Figure 5. The synthesis of ZnONPs is represented by distinct peaks observed for zinc and oxygen and carbon atoms. The atomic percentages of the elements inset of Figure 5 indicated zinc as the dominant element, representing more than $72.49 \%$ of the entire composition, with oxygen representing $27.51 \%$, indicating that the ZnONPs were extremely pure.

\subsubsection{Fourier Transforms Infrared Spectroscopy (FTIR) Analysis}

The interfaces between zinc oxide and bioactive components of fungal extract were discovered using FTIR on green synthesized ZnONPs. It was carried out to discover the organic functional groups or potential biomolecules involved in the production of ZnONPs. In the present results, FTIR spectrum showed 3398, 3233, 2912, 1640, 1629, 1561, 1461, 1018, 576 and $533 \mathrm{~cm}^{-1}$ (Table 2). In FTIR spectrum, the peak observed at $3398 \mathrm{~cm}^{-1}$ corresponded to $\mathrm{OH}$ stretching vibrations and 3233, peak observed at 3323 responding to $\mathrm{C}-\mathrm{H}$ stretch of alkenyl and 1640 corresponded to $\mathrm{C}=\mathrm{O}$ stretching 1629 responding to $-\mathrm{C}=\mathrm{C}-$ aromatic stretching of fungal biomass and 1561 responding to $\mathrm{C}=\mathrm{C}$ stretch in the aromatic ring and $\mathrm{C}=\mathrm{O}$ stretch in polyphenols and 1461 corresponded to $\mathrm{C}-\mathrm{N}$ stretch of amide-I in protein and 1018 responding to C-O stretching in amino acid, while 576 and 533 corresponded $\mathrm{Zn}-\mathrm{O}$ stretching and hexagonal phase $\mathrm{ZnO}$ respectively. 

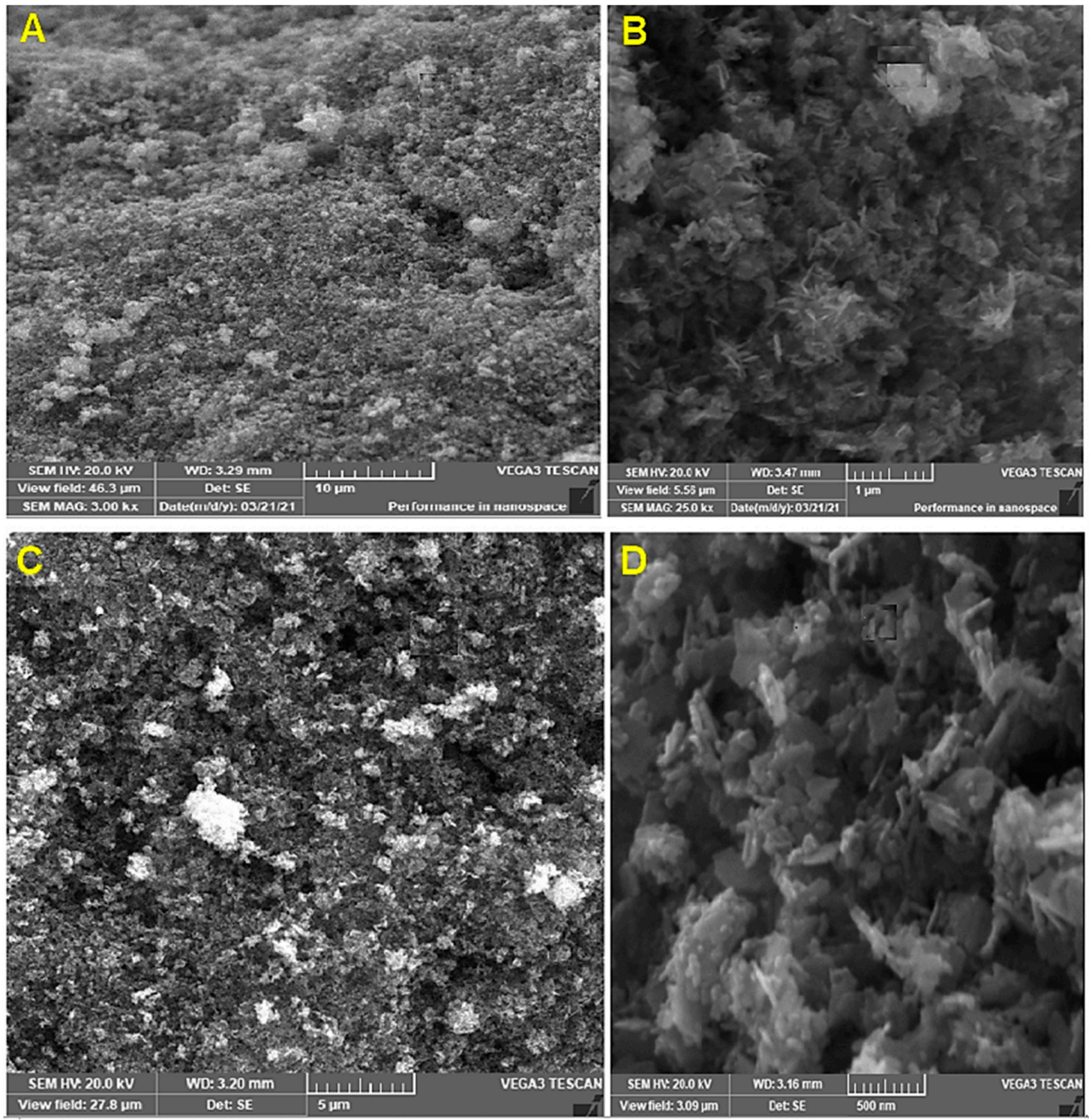

Figure 4. Scanning electron microscope micrographs at different magnifications, (A) 10, (B) 5, (C) $1 \mu \mathrm{m}$ and (D) $500 \mathrm{~nm}$ of Trichogenic-ZnONPs.

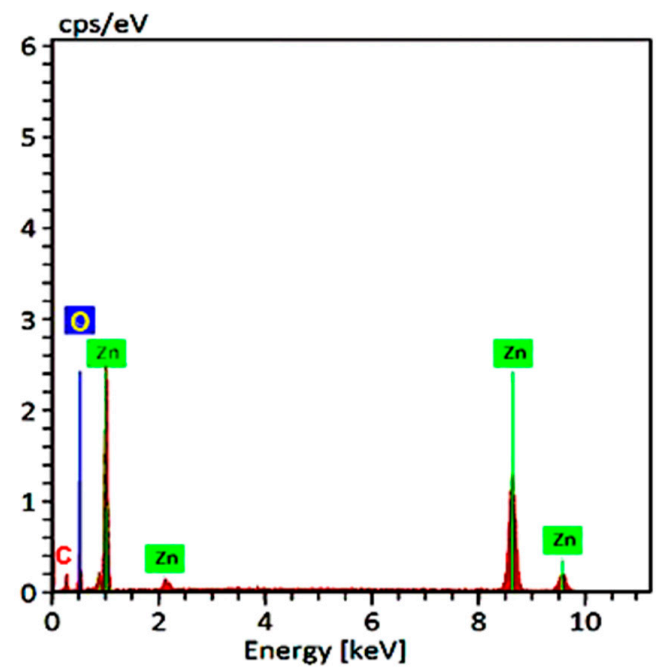

Figure 5. Elemental and energy dispersive X-ray spectroscopic analysis of Trichogenic-ZnONPs. 
Table 2. Functional Group present in the Trichogenic ZnONPs analyzed by FTIR.

\begin{tabular}{cccc}
\hline & Frequency $\mathbf{( c m})^{-1}$ & Abs & Possible Assignment \\
\hline 1 & 3398.9229 & 96.32 & OH stretching vibrations \\
2 & 3233.0747 & 97.1775 & C-H stretch of alkanyle \\
3 & 2912.9492 & 97.6787 & The C-H stretch in alkanes \\
4 & 2854.1311 & 97.3885 & O-H stretch in a carboxylic acid \\
5 & 1640.1611 & 99.027 & C=O stretching \\
6 & 1629.5546 & 99.0942 & -C=C- aromatic stretching of fungal biomass \\
7 & 1613.1626 & 98.9696 & H-O-H binding vibration \\
8 & 1561.094 & 98.5039 & C=C stretch in the aromatic ring and C=O stretch in polyphenols \\
9 & 1556.2728 & 98.4978 & C=C/amine-NH stretching \\
10 & 1461.778 & 98.8046 & C-N stretch of amide-I in protein \\
11 & 1382.7108 & 99.117 & Acetate group stretching \\
12 & 1034.6226 & 96.4734 & O-H Asymmetric stretching \\
13 & 1018.2305 & 96.3747 & C-O stretching in amino acid \\
14 & 929.5211 & 97.4376 & C-N stretching amine \\
15 & 773.3152 & 98.6183 & C-N stretching amine \\
16 & 576.6116 & 95.2955 & Zn-O stretching \\
17 & 533.2211 & 88.8474 & hexagonal phase ZnO \\
\hline
\end{tabular}

\subsection{In Vitro Antifungal Activity of Synthesized ZnONPs}

The potentiality of ZnONPs for controlling R. solani (RS9), Fusarium sp. (F10) and M. phaseolina (M4) was tested by plating the fungal culture media supplemented with (control), 20,40 and $100 \mu \mathrm{g} / \mathrm{mL}$ of $\mathrm{ZnONPs}$ and the diameter of the mycelium growth was measured after 7 days. ZnONPs caused a significant reduction in the mycelia growth of R. solani (RS9), Fusarium sp. (F10) and M. phaseolina (M4) by all concentrations. As shown in (Figure 6), under the effect of ZnONPs treatments, the mycelial diameter of $R$. solani (RS9), Fusarium sp. (F10) and M. phaseolina (M4) was reduced by $100 \%$ at all the tested concentrations.

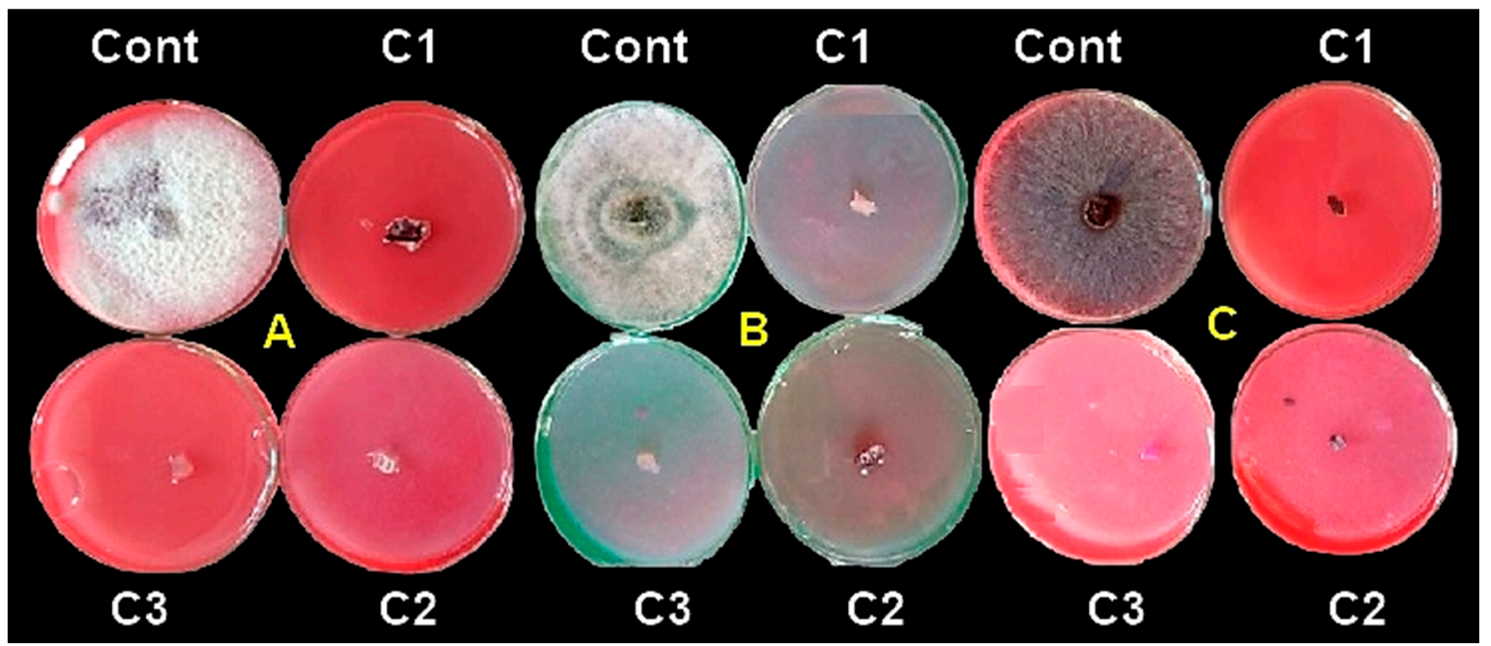

Figure 6. The inhibitory effect of mycelia growth on F10 (A), Rs9 (B), M4 (C) on potato dextrose agar medium containing ZnONPs at concentrations: Control, (C1) 20, (C2) 40 and (C3) $100 \mu \mathrm{g} / \mathrm{mL}$ after 7 days.

\subsection{Effect of ZnONPs against Cotton Damping-Off Disease under Greenhouse Conditions}

The effects of ZnONPs on the cotton seedling disease were studied in a greenhouse experiment. In a greenhouse, four treatments were tested for their ability to reduce cotton seedling disease produced by three pathogenic isolates (F10, Rs9 and M4). The number of surviving seedlings increased. Analysis of variance (ANOVA) (Table 3) showed that the treatment was a very highly significant source of variation $(p=0.00)$ of all the tested variables. Fungus $\times$ treatment interaction was a very highly significant source of variation 
$(p=0.00)$ only in the case of plant height. The effect of fungus was a non-significant source of variation in all the tested variables.

Table 3. Analysis of variance of the effect of some fungi, treatments and their interaction on some growth variables of cotton seedlings of Giza90 grown in soil infested under greenhouse conditions.

\begin{tabular}{|c|c|c|c|c|}
\hline Growth Variables and Sources of Variation & D.F & Mean Square & F Value & $p \geq \mathbf{F}$ \\
\hline \multicolumn{5}{|l|}{ Survival } \\
\hline Replicates & 2 & 118.51 & 0.51 & 0.61 \\
\hline Fungi (F) & 2 & 78.65 & 0.34 & 0.72 \\
\hline Treatments $(\mathrm{T})$ & 5 & 3944.66 & 16.91 & 0.00 \\
\hline $\mathrm{F} \times \mathrm{T}$ & 10 & 127.82 & 0.55 & 0.84 \\
\hline Error & 34 & 23.22 & & \\
\hline \multicolumn{5}{|l|}{ Plant height } \\
\hline Replicates & 2 & 3.72 & 0.31 & 0.74 \\
\hline Fungi (F) & 2 & 17.95 & 1.49 & 0.24 \\
\hline Treatments $(\mathrm{T})$ & 5 & 244.83 & 20.25 & 0.00 \\
\hline $\mathrm{F} \times \mathrm{T}$ & 10 & 50.89 & 4.21 & 0.00 \\
\hline Error & 34 & 12.09 & & \\
\hline Dry weight & 2 & & & \\
\hline Replicates & 2 & 0.22 & 0.90 & 0.42 \\
\hline Fungi (F) & 5 & 0.32 & 1.30 & 0.29 \\
\hline Treatments (T) & 10 & 4.13 & 16.7 & 0.00 \\
\hline $\mathrm{F} \times \mathrm{T}$ & 34 & 0.23 & 0.94 & 0.51 \\
\hline Error & 2 & 0.25 & & \\
\hline
\end{tabular}

Since there was no fungus $\times$ treatment interaction on survival (Table 4), the general mean was used to compare treatment means. Seeds of Giza90 treated with ZnONPs $(200 \mu \mathrm{g} / \mathrm{mL})$ showed the maximum efficiency in controlling disease regardless of fungus ( $91.111 \%$ survival). The difference between the general means of the tested fungi was non-significant.

Table 4. Effect of some fungi, treatments and their interaction on survival percentage of cotton seedlings of Giza90 grown in infested soil under greenhouse conditions.

\begin{tabular}{|c|c|c|c|c|c|c|c|c|}
\hline \multicolumn{9}{|c|}{ ZnO/Survival/Giza90 (\%) } \\
\hline \multirow{2}{*}{ Treatment } & \multicolumn{2}{|r|}{ F10 } & \multicolumn{2}{|c|}{ Rs9 } & \multicolumn{2}{|r|}{ M4 } & \multicolumn{2}{|c|}{ Mean } \\
\hline & $\%$ & Transformed $^{\mathrm{a}}$ & $\%$ & Transformed $^{\mathrm{a}}$ & $\%$ & Transformed $^{\mathrm{a}}$ & $\%$ & Transformed $^{a}$ \\
\hline ZnONPs $(\mu \mathrm{g} / \mathrm{mL})$ & 76.667 & 61.910 & 80.000 & 63.440 & 53.333 & 46.910 & 70.000 & 57.420 \\
\hline ZnONPs $(\mu \mathrm{g} / \mathrm{mL})$ & 96.667 & 83.853 & 93.333 & 81.147 & 83.333 & 70.077 & 91.111 & 78.359 \\
\hline Maxim XL (2 mL) & 86.667 & 72.293 & 86.667 & 72.783 & 90.000 & 75.000 & 87.778 & 73.359 \\
\hline Moncut (2 g) & 86.667 & 72.783 & 83.333 & 70.763 & 83.333 & 66.147 & 84.444 & 69.898 \\
\hline Infested soil & 30.000 & 28.077 & 16.667 & 15.000 & 26.667 & 30.293 & 24.445 & 24.457 \\
\hline Autoclaved soil & 30.000 & 28.077 & 16.667 & 15.000 & 26.667 & 30.293 & 24.445 & 24.457 \\
\hline Mean & 77.778 & 65.653 & 76.111 & 64.498 & 71.667 & 61.596 & 75.185 & 63.916 \\
\hline
\end{tabular}

$\operatorname{LSD}(p \leq 0.05)$ (transformed data) for treatments $=14.25$. LSD $(p \leq 0.05)$ for fungus is non-significant. ${ }^{\text {a }}$ Percentage of data were transformed into arcsine angles before carrying out the analysis of variance to produce an approximately constant variance.

Because cultivar $\times$ treatment interaction was significant on plant height (Table 5), an interaction LSD was calculated to compare treatment means within each tested fungus. All treatments were effective in controlling disease compared to the infested control. The high concentrations of ZnONPs showed the maximum efficiency in controlling the disease for all tested fungi $(25.193,26.433$ and $24.767 \mathrm{~cm})$ for F10, Rs9 and M4, respectively. Since there was no fungus $\times$ treatment interaction on dry weight (Table 6), the general mean was used to compare treatment means. Seeds of Giza90 treated with ZnONPs $(200 \mu \mathrm{g} / \mathrm{mL})$ showed the maximum efficiency in controlling disease regardless of fungus $(2.200 \mathrm{~g})$. The difference between the general means of the tested fungi was non-significant. 
Table 5. Effect of some fungi, treatments and their interaction on plant height of cotton seedlings of Giza90 grown in infested soil under greenhouse conditions.

\begin{tabular}{|c|c|c|c|c|}
\hline \multicolumn{5}{|c|}{ ZnO/Plant Height (cm)/Giza90 } \\
\hline Treatment & F10 & Rs9 & M4 & Mean \\
\hline ZnONPs $(100 \mu \mathrm{g} / \mathrm{mL})$ & 17.267 & 21.797 & 18.387 & 19.150 \\
\hline ZnONPs $(200 \mu \mathrm{g} / \mathrm{mL})$ & 25.193 & 26.433 & 24.767 & 25.464 \\
\hline Maxim XL (2 mL) & 18.573 & 21.843 & 15.917 & 18.778 \\
\hline Moncut (2 g) & 20.147 & 16.627 & 21.137 & 19.304 \\
\hline Infested soil & 7.150 & 4.800 & 20.303 & 10.751 \\
\hline Autoclaved soil & 24.307 & 24.833 & 23.847 & 24.329 \\
\hline Mean & 18.773 & 19.389 & 20.726 & 19.629 \\
\hline
\end{tabular}

$\operatorname{LSD}(p \leq 0.05)$ for fungus $\times$ treatment $=5.62$.

Table 6. Effect of some fungi, treatments and their interaction on the dry weight of cotton seedlings of Giza90 grown in soil infested under greenhouse conditions.

\begin{tabular}{ccccc}
\hline & \multicolumn{3}{c}{ ZnO/Dry Weight (g)/Giza90 } & M4 \\
\hline Treatment & F10 & Rs9 & 1.370 & 1.521 \\
ZnONPs $(100 \mu \mathrm{g} / \mathrm{mL})$ & 1.700 & 1.493 & 1.973 & 2.200 \\
ZnONPs $(200 \mu \mathrm{g} / \mathrm{mL})$ & 2.250 & 2.377 & 1.137 & 1.579 \\
Maxim XL $(2 \mathrm{~mL})$ & 2.073 & 1.527 & 1.137 & 1.543 \\
Moncut $(2 \mathrm{~g})$ & 1.660 & 1.833 & 0.377 & 0.232 \\
Infested soil & 0.187 & 0.133 & 2.090 & 1.933 \\
Autoclaved soil & 1.660 & 2.050 & 1.347 & 1.501 \\
Mean & 1.588 & 1.569 & \\
\hline
\end{tabular}

$\operatorname{LSD}(p \leq 0.05)$ for treatments $=0.47$. LSD $(p \leq 0.05)$ for fungus is non-significant.

Analysis of variance (ANOVA) of Table 7 showed that treatment was a very highly significant source of variation $(p=0.00)$ of all the tested variables. Fungus and fungus $\times$ treatment interaction was non-significant sources of variation of all the tested variables.

Table 7. Analysis of variance of the effect of some fungi, treatments and their interaction on some growth variables of cotton seedlings of Giza94 grown in soil infested under greenhouse conditions.

\begin{tabular}{|c|c|c|c|c|}
\hline Growth Variables and Sources of Variation & D.F. & Mean Square & F. Value & $p \geq \mathbf{F}$ \\
\hline \multicolumn{5}{|l|}{ Survival } \\
\hline Replicates & 2 & 556.02 & 2.79 & 0.08 \\
\hline Fungi $(\mathrm{F})$ & 2 & 19.16 & 0.10 & 0.91 \\
\hline Treatments $(\mathrm{T})$ & 5 & 4674.53 & 23.45 & 0.00 \\
\hline $\mathrm{F} \times \mathrm{T}$ & 10 & 215.36 & 1.08 & 0.40 \\
\hline Error & 34 & 199.32 & & \\
\hline \multicolumn{5}{|l|}{ Plant height } \\
\hline Replicates & 2 & 38.05 & 1.37 & 0.27 \\
\hline Fungi (F) & 2 & 23.36 & 0.84 & 0.44 \\
\hline Treatments (T) & 5 & 320.18 & 11.52 & 0.00 \\
\hline $\mathrm{F} \times \mathrm{T}$ & 10 & 36.91 & 1.33 & 0.26 \\
\hline Error & 34 & 27.80 & & \\
\hline Dry weight & 2 & & & \\
\hline Replicates & 2 & 0.42 & 1.32 & 0.28 \\
\hline Fungi (F) & 5 & 0.14 & 0.46 & 0.64 \\
\hline Treatments $(\mathrm{T})$ & 10 & 4.99 & 15.77 & 0.00 \\
\hline $\mathrm{F} \times \mathrm{T}$ & 34 & 0.33 & 1.04 & 0.43 \\
\hline Error & 2 & 0.32 & & \\
\hline
\end{tabular}

Since there were no effects of fungus $\times$ treatment interaction on survival (Table 8 ), the general mean was used to compare treatment means. Seeds of Giza94 treated with Moncut 
( $2 \mathrm{~g}$ ) showed the maximum efficiency in controlling disease regardless of fungus $(88.889 \%$ survival) followed by Maxim XL ( $2 \mathrm{~mL})$ and ZnONPs $(200 \mu \mathrm{g} / \mathrm{mL})$. The difference between the general means of the tested fungi was non-significant (Figure 7).

Table 8. Effect of some fungi, treatments and their interaction on survival percentage of cotton seedlings of Giza94 grown in soil infested under greenhouse conditions.

\begin{tabular}{|c|c|c|c|c|c|c|c|c|}
\hline \multicolumn{9}{|c|}{ ZnO/Survival/Giza94 (\%) } \\
\hline \multirow{2}{*}{ Treatment } & \multicolumn{2}{|r|}{ F10 } & \multicolumn{2}{|r|}{ Rs9 } & \multicolumn{2}{|r|}{ M4 } & \multicolumn{2}{|c|}{ Mean } \\
\hline & $\%$ & Transformed $^{a}$ & $\%$ & Transformed $^{a}$ & $\%$ & Transformed $^{a}$ & $\%$ & Transformed $^{a}$ \\
\hline ZnONPs $(100 \mu \mathrm{g} / \mathrm{mL})$ & 36.667 & 36.930 & 10.000 & 11.070 & 43.333 & 41.057 & 30.000 & 29.686 \\
\hline ZnONPs $(200 \mu \mathrm{g} / \mathrm{mL})$ & 73.333 & 59.693 & 73.333 & 59.693 & 76.667 & 61.223 & 74.444 & 60.203 \\
\hline Maxim XL $(2 \mathrm{~mL})$ & 80.000 & 67.860 & 76.667 & 65.840 & 76.667 & 61.910 & 77.778 & 65.203 \\
\hline Moncut (2 g) & 83.333 & 70.077 & 93.333 & 77.707 & 90.000 & 75.000 & 88.889 & 74.261 \\
\hline Infested soil & 16.667 & 19.223 & 30.000 & 28.077 & 6.667 & 12.293 & 17.778 & 19.864 \\
\hline Autoclaved soil & 86.667 & 72.783 & 86.667 & 72.293 & 83.333 & 66.147 & 85.556 & 70.408 \\
\hline Mean & 62.778 & 54.428 & 61.667 & 52.447 & 62.778 & 52.938 & 62.408 & 53.271 \\
\hline
\end{tabular}

LSD ( $p \leq 0.05)$ (transformed data) for treatments $=13.18$. LSD $(p \leq 0.05)$ for fungus is non-significant. ${ }^{\text {a }}$ Percentage data were transformed into arcsine angles before carrying out the analysis of variance to produce an approximately constant variance.

Since there was no fungus $\times$ treatment interaction on plant height and dry weight (Tables 9 and 10), the general mean was used to compare treatment means. Seeds of Giza94 treated with ZnONPs $(200 \mu \mathrm{g} / \mathrm{mL})$ showed the maximum efficiency in controlling disease regardless of fungus ( $24.300 \mathrm{~cm}$ and $2.094 \mathrm{~g}$ ). The difference between the general means of the tested fungi was non-significant.

Table 9. Effect of some fungi, treatments and their interaction on plant height of cotton seedlings of Giza94 grown in infested soil under greenhouse conditions.

\begin{tabular}{|c|c|c|c|c|}
\hline \multicolumn{5}{|c|}{ ZnO/Plant Height (cm)/Giza94 } \\
\hline Treatment & F10 & Rs9 & M4 & Mean \\
\hline ZnONPs $(100 \mu \mathrm{g} / \mathrm{mL})$ & 19.527 & 4.887 & 14.830 & 13.081 \\
\hline ZnONPs $(200 \mu \mathrm{g} / \mathrm{mL})$ & 25.377 & 22.557 & 24.967 & 24.300 \\
\hline Maxim XL (2 mL) & 19.113 & 22.713 & 18.997 & 20.274 \\
\hline Moncut (2 g) & 21.333 & 22.653 & 17.973 & 20.653 \\
\hline Infested soil & 11.917 & 11.533 & 11.000 & 11.483 \\
\hline Autoclaved soil & 26.730 & 26.950 & 25.507 & 26.396 \\
\hline Mean & 20.666 & 18.549 & 18.879 & 19.365 \\
\hline
\end{tabular}

$\operatorname{LSD}(p \leq 0.05)$ for treatments $=4.92 ., \operatorname{LSD}(p \leq 0.05)$ for fungus is non-significant.

Table 10. Effect of some fungi, treatments and their interaction on the dry weight of cotton seedlings of Giza94 grown in infested soil under greenhouse conditions.

\begin{tabular}{ccccc}
\hline & \multicolumn{3}{c}{ ZnO/Dry Weight (g)/Giza94 } & Mean \\
\hline Treatment & F10 & Rs9 & M4 & 1.166 \\
ZnONPs $(100 \mu \mathrm{g} / \mathrm{mL})$ & 1.427 & 0.507 & 1.563 & 2.094 \\
ZnONPs $(200 \mu \mathrm{g} / \mathrm{mL})$ & 2.253 & 2.170 & 1.860 & 1.593 \\
Maxim XL $(2 \mathrm{~mL})$ & 1.537 & 1.753 & 1.360 & 1.518 \\
Moncut $(2 \mathrm{~g})$ & 1.697 & 1.497 & 0.537 & 0.549 \\
Infested soil & 0.403 & 0.707 & 2.270 & 2.709 \\
Autoclaved soil & 2.837 & 3.020 & 1.513 & 1.605 \\
Mean & 1.692 & 1.609 & \\
\hline
\end{tabular}

$\operatorname{LSD}(p \leq 0.05)$ for treatments $=0.53$. LSD $(p \leq 0.05)$ for fungus is non-significant. 


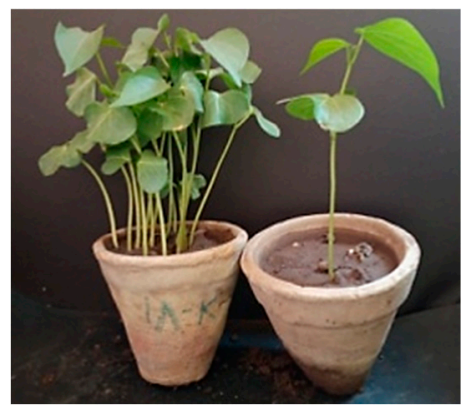

Control, infested control,

\section{Giza90}

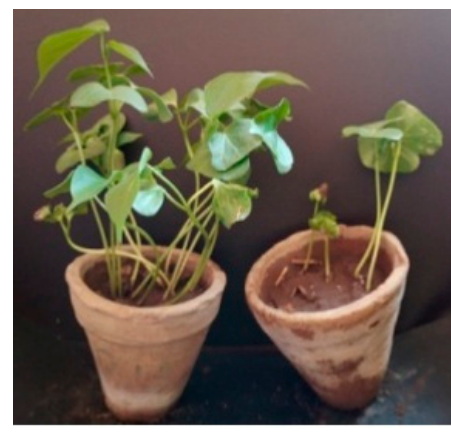

Control, infested control, Giza 93

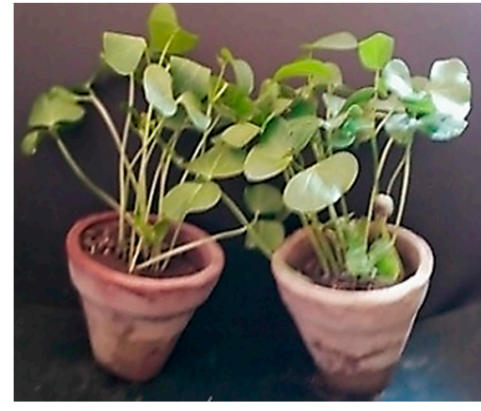

Maxim XL, Moncut

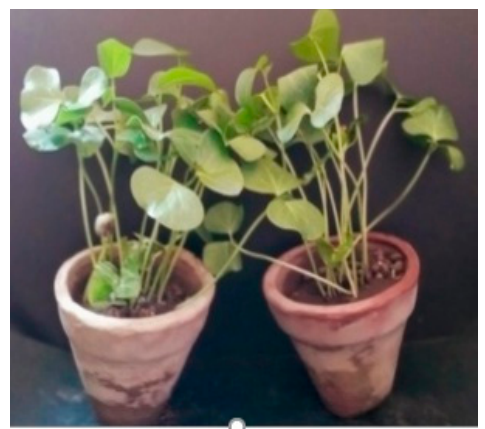

Maxim XL, Moncut

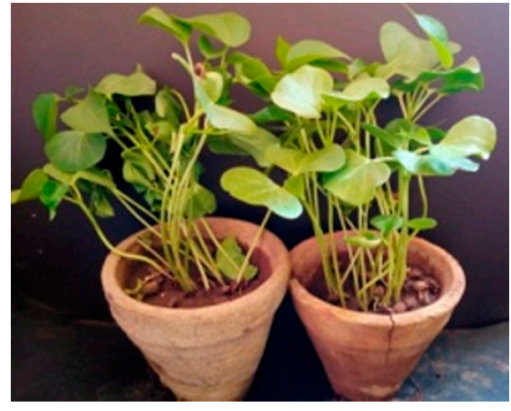

Fusarium (F10)

ZnONPs 100, 200 g/mL

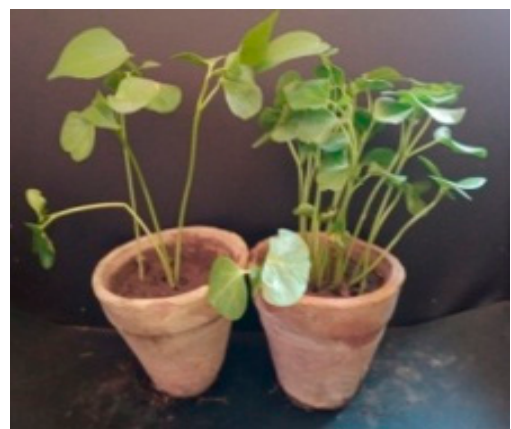

Fusarium (F10)

ZnONPs 100, 200 g/mL

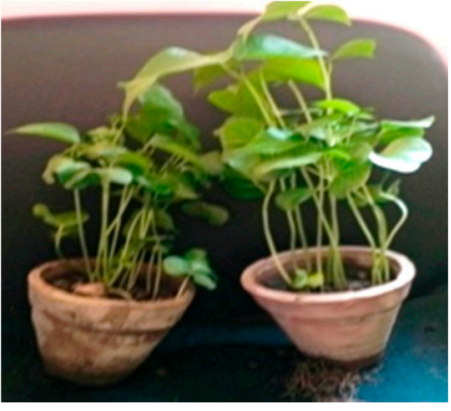

Rhizoctonia (RS9)

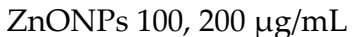

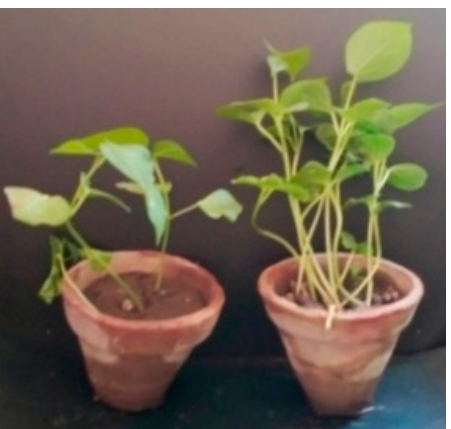

Rhizoctonia (RS9)

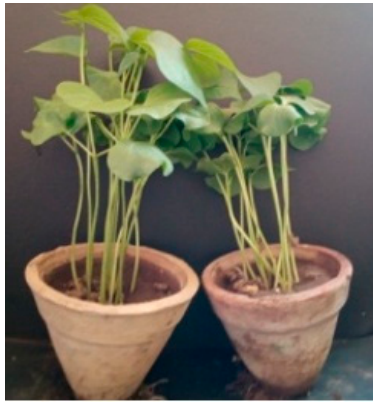

Macrophomina (M4)

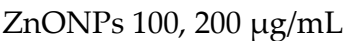

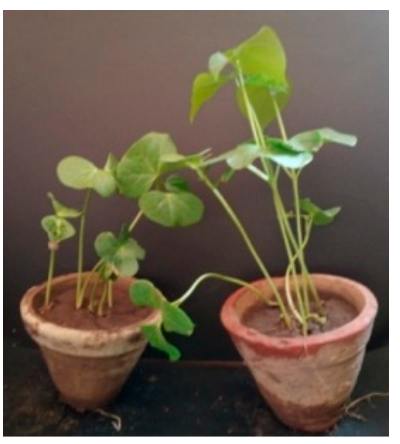

Macrophomina (M4)

ZnONPs 100, 200 g/mL

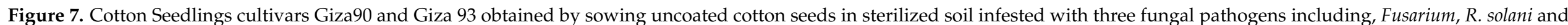

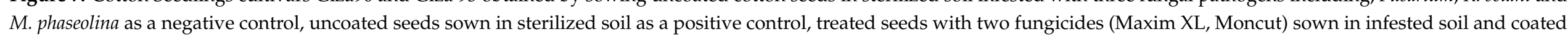
seeds with ZnONPs (100, $200 \mu \mathrm{g} / \mathrm{mL})$ in infested soil. Photos were taken after 45 days under standard growth conditions in greenhouse conditions. 


\section{Discussion}

Nanoparticles derived from Trichoderma are still in the early stages of research. Mycogenic ZnONPs utilizing Trichoderma sp. are more compelling and less harmful to the environment than other methods. Therefore, ZnONPs produced utilizing a cell-free aqueous filtrate of T. harzianum were shown to have strong antifungal efficacy against the soil-borne pathogen complexes in cotton in this investigation. To confirm whether the synthesized nanoparticles were still stable for one week or changed in the UV results, the absorption spectrum was recorded for the synthesized $\mathrm{ZnO}$ sample by Tvivi, T34 and T28 after 2, 4 and 7 days after synthesis. The UV-visible spectrum showed the absorbance peak at $300 \mathrm{~nm}$ corresponding to the characteristic band of zinc oxide nanoparticles for all screened Trichoderma isolates at all tested periods. The obtained UV-vis spectrophotometer results were in agreement with Dobrucka et al. [33], who reported that the maximum absorption of about $310 \mathrm{~nm}$, which is a characteristic band of pure $\mathrm{ZnO}$, verified the presence of $\mathrm{ZnONPs}$ biologically with the use of the extract of Chelidonium majus. Furthermore, there was no additional peak in the spectrum, confirming that the produced products were pure $\mathrm{ZnO}$ [34,35]. In addition, Perveen et al. [36] reported that UV-visible spectroscopy investigation showed a peak at $300 \mathrm{~nm}$, which corresponded to the wavelength of $\mathrm{ZnO}$ quantum dots' surface plasmon resonance. The UV-vis spectra of ZnONPs synthesized by A. niger show that at $390 \mathrm{~nm}, \mathrm{ZnONPs}$ have a high absorption spectra [37]. Jamdagni et al. [38] found that the UV spectrum range of ZnONPs is $320-390 \mathrm{~nm}$, which is a similar result.

The XRD diffraction peaks were $31.84^{\circ}, 34.52^{\circ}, 36.33^{\circ}, 47.63^{\circ}, 56.71^{\circ}, 62.96^{\circ}, 68.13^{\circ}$, $69.18^{\circ}, 70.16^{\circ}, 73.21^{\circ}$ and $78.56^{\circ}$, which agreed with Sadatzadeh et al., Yedurkar et al. and Malaikozhundanet al. [39-41]. The peaks showed the characteristic hexagonal wurtzite structure of ZnO (JCPDS card no. 36-1451) [42]. The Wurtzite structure was prevalent because it is stable in ambient conditions. It also revealed that the synthesized nanopowder was impurity-free because it lacked any XRD peaks other than zinc oxide peaks. The XRD diffraction peaks matched well with Wurtzite $\mathrm{ZnO}$ of the Joint Committee on Powder Diffraction Standards (JCPDS) Card number 36-1451 and were in good accord with the reported literature [43].

The magnitude of the Zeta potential $(-30 \mathrm{mV}$ to $+30 \mathrm{mV})$ indicates the potential stability of the colloidal system [44-46]. The Zeta potential is related to the nanoparticles' stability in the solution. The larger zeta potential values represent a lower degree of aggregation that leads to a higher degree of stability of nanoparticles and a smaller zaveraged hydrodynamic diameter. At lower zeta values, the nanoparticles flocculate early and the stability of the nano-suspension reduces [44]. The Zeta potential of ZnONPsin the present study was $-24.0 \mathrm{mV}$, which provided evidence that the fabricated nanoparticles were moderately stable, which led to the monodispersity of the particles. The result was in agreement with Divya et al. [45], who showed a zeta potential of $-5.36 \mathrm{mV}$. Furthermore, Zakharova [46] reported a zeta potential of $9 \mathrm{mV}$ of ZnONPs had high antimicrobial efficacy and increased $\mathrm{ZnONPs}$ toxicity. It has been proven that some nanoparticles have a tendency to aggregate and that this process of aggregation reduces the surface area of nanoparticles. To solve this problem, $\mathrm{ZnONPs}$ require extensive ultrasonication in the water bath for a minimum of $15 \mathrm{~min}$.

The results were in agreement with González et al. [47], who reported that TEM analysis of the synthesized ZnONPs showed spherical, hexagonal and rod shapes. Pillai et al. [48] reported that the synthesized ZnONPs from an aqueous extract of Beta vulgaris were spherical with a size of nearly $20 \pm 2 \mathrm{~nm}$. Morphology of bio nanoparticles produced from Cinnamomum tamala was rod-shaped, the particles size within the range $30 \pm 3 \mathrm{~nm}$.

TEM results of biosynthesized ZnONPs by Anacardium occidentale leaf extract confirmed the hexagonal structure with an average particle size of $33 \mathrm{~nm}$ [49]. Our results are in harmony with Ruddaraju et al. [50]. The results were in agreement with Ruddaraju et al. and Javed et al. [50,51]. The SEM images described surface topological details of different nano-objects based on the electron density of the surface due to their higher resolution 
and bigger field depth [52]. The agglomeration of ZnONPs might be attributed either due to its polarity and electrostatic attraction between $\mathrm{ZnONPs}$ or due to the high surface energy of ZnONPs. The high surface energy of ZnONPs could be originated from an aqueous synthetic medium [53-55]. TEM is used to magnify an image by using electromagnetic lenses to magnify an electron beam that travels through thin specimens in a nearly parallel manner. The objective lens is the principal electromagnetic lens. For example, an SEM picture generally shows bigger agglomerated particles, but TEM images have a greater resolution. This means that TEM is superior to SEM in terms of its ability to measure the nanoparticles' size and has a greater resolution than SEM [54]. EDX analysis is a chemical microanalysis technique that is used in conjunction with SEM to evaluate elemental composition by detecting $X$-rays released from the sample during electron beam bombardment [55]. EDX analysis was in good agreement with XRD results. The EDX results of the present study were in agreement with several reports $[36,39,40]$. The FTIR spectrum revealed 3398, 3233, 2912, 1640,1629, 1561, 1461, 1018, 576 and $533 \mathrm{~cm}^{-1}$ in the current study. The peak at 1640 corresponded to $\mathrm{C}=\mathrm{O}$ stretching of the functional group. The peak in the range 1556 corresponded to $\mathrm{C}=\mathrm{C} /$ amine $-\mathrm{NH}$ stretching of the aromatic compound [55].

The wide peak at $3233 \mathrm{~cm}^{-1}$ may be attributed to an alkenyl group's C-H stretch, whereas $2104 \mathrm{~cm}^{-1}$ was moved to $-\mathrm{C} \equiv \mathrm{C}-$ stretching vibrations [40]. Secondary metabolites found in C. roseus have been linked to the conversion of zinc acetate dihydrate to zinc oxide nanoparticles. The FTIR spectrum showed peaks at 3233, 2104, 1640, 1556, 1399, $1086,926,773,849,715,1035,482,410 \mathrm{~cm}^{-1}$ [56]. Due to stretching alkenyl groups formed by zinc acetate salts and their reduction in ZnONPs, the FTIR spectra peak showed highintensity broadband of $3233 \mathrm{~cm}^{-1}[37,56]$. According to the results of our FTIR analysis, Trichoderma-mediated $\mathrm{ZnONPs}$ were synthesized using two distinct processes: reduction and capping. On the surfaces of both the biosynthesized ZnONPs that function as reducing and stabilizing agents, FTIR examination indicated the presence of proteins, amino acids, polyphenols, carboxyl and hydroxyl groups. ZnONPs are characterized by their strong aromatic ring and carboxylic acid appearance in the FTIR bands. According to the results of the FTIR analysis described various mycochemicals such as phenolic, proteins, amino acids, aldehydes, ketone and other functional groups were involved in the reduction, capping and stabilization of zinc oxide NPs (Figure 8).

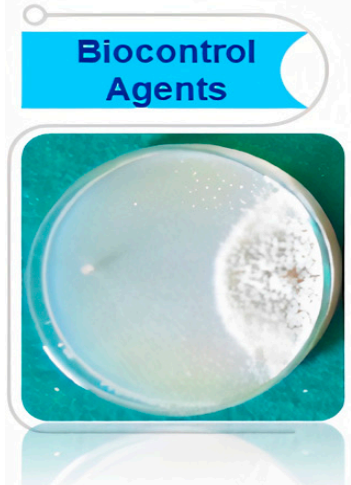

Select higly efficients starins

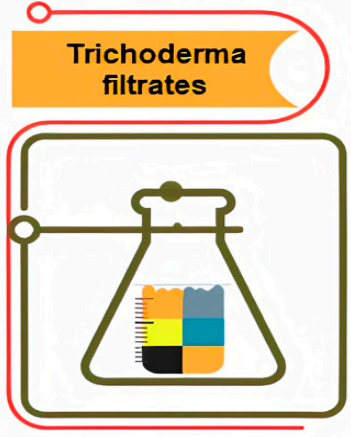

Production culture filtrates

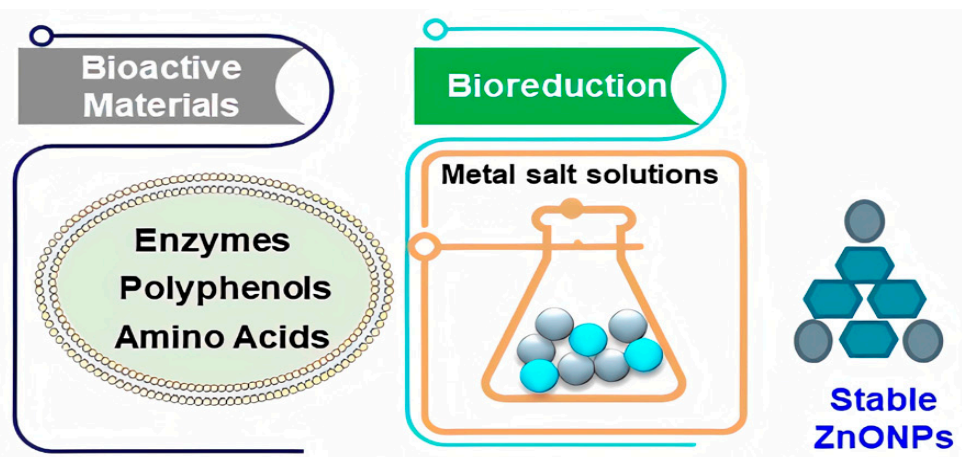

Use capping and stablizing agents to syntesis

Chracterize bioactive agents

Figure 8. A schematic illustration depicting the methods used by Trichoderma harzianum strains to produce green zinc oxide nanoparticles.

In in vitro assay, in addition to inhibiting the vegetative mycelial growth of phytopathogenic fungi, zinc-mediated nanoparticles or composites can kill spores or inhibit spore germination (sporostatic/sporicidal activities) at low concentrations, such as a significant decrease in fungal growth of B. cinerea and P. expansum shown on ZnONPs ( $3 \mathrm{mM} / \mathrm{L}$ concentration) treatment [57]. Yehia and Ahmed [58] reported the antifungal efficiency of ZnONPs investigated against F. oxysporum. The maximum inhibition of mycelial growth 
was seen at $(12 \mathrm{mg} / \mathrm{L})$ when F. oxysporum growth was inhibited by 77 percent. HPLC quantification was used to study the influence of ZnONPs on the mycotoxin fusaric acid. The amount of fusaric acid was lowered from 39.0 to $0.20 \mathrm{mg} / \mathrm{g}$. Scanning electron microscopy showed evident deformation in mycelia that had been treated with ZnONPs in F. oxysporum, which may cause growth inhibition.

In the present work, in vitro assay, zero fungal growth was investigated with concentrations starting from $20 \mu \mathrm{g} / \mathrm{mL}$ of ZnONPs. Fungicidal properties against three pathogenic fungi were explored in our study. Due to the current dearth of understanding of different aspects of fungal disease biology, these antifungal properties are currently restricted. Lahuf et al. [24] found that a concentration of $15 \mathrm{mg} / \mathrm{mL}$ led to complete inhibition (100\%) of $R$. solani; however, lower doses of ZnONPs (10,5 and $2.5 \mathrm{mg} / \mathrm{mL})$ resulted in lower levels of inhibition of $R$. solani, by 83.21, 71.03 and 57 percent inhibition, respectively. Furthermore, it was discovered that ZnONPs have fungistatic rather than deadly fungicidal effects on $R$. solani. The ZnONPs fungicidal properties revealed that they were diffusible via the growing media [59]. Shen et al. and Raghupathi et al. [60,61] documented the antifungal effects of $\mathrm{ZnONPs}$ on microbial populations. It was suggested that zero-valent metal nanoparticles might successfully permeate pathogenic microorganism cell membranes through the lipid bilayer because of their reduced hydrophobicity due to the absence of surface charge [62]. $\mathrm{ZnO}$ showed obvious destruction of the cell walls and plasmolysis of the internal organs of the tested fungi [63]. In vitro studies against F. oxysporum, R. solani and Sclerotium rolfsii revealed that a mixture of Trichoderma asperellum and chitosan nanoparticles was better than Trichoderma alone and carbendazim $0.1 \%$ in suppressing pathogen mycelial growth [64].

In the current study, under greenhouse conditions, the results of the disease management studies of zinc oxide NPs, at two different concentrations (100 and $200 \mu \mathrm{g} / \mathrm{mL})$, seed treatments for efficacy in the control of damping-off in cotton, compared to Maxim XL and Moncut chemical fungicides, indicated that ZnONPs $(200 \mu \mathrm{g} / \mathrm{mL})$, gave the maximum efficiency in disease control, compared to other treatments in Giza90 for all growth parameters (survival, plant height and dry weight). However, in the case of Giza94 cultivars, ZnONPs $(200 \mu \mathrm{g} / \mathrm{mL})$ NPs were not the best treatment in disease control in the case of survival only. However, it increased the survival significantly compared to infested control, but it was the best treatment in the case of plant height and dry weight. These results indicated that ZnONPs behavior was affected by the cultivar and it may need to be used at different optimum concentrations according to cotton cultivars to give the maximum survival during further future studies. The ZnONPs may form an antifungal layer around cotton seeds that protects cotton seedlings from the three pathogenic fungi. When ZnONPswas used as an antifungal agent against $R$. solani at concentrations of 30,60 and $90 \mathrm{~g} \mathrm{~mL}^{-1}$, the second and the third concentration raised the percentages of Giza90 seedlings that survived to 85 and $86 \%$, respectively, compared to 43.5 percent persisted seedlings at the concentration of $30 \mathrm{~g} \mathrm{~m}^{-1}$ [65]. González-Merino et al. [66] evaluated the antifungal activity of ZnONPs against F.oxysporum on tomato plants under greenhouse conditions. ZnONPs from 1500 to $3000 \mathrm{~g} / \mathrm{mL}$ achieved the best plant height with a range of 166.0 to $175.40 \mathrm{~cm}$, a severity of $0.40-0.80$ and a disease incidence of $20-40 \%$. In a pot experiment, foliar spraying of ZnONPs was more successful than seed priming in enhancing plant dry weight and controlling the Pectobacterium betavasculorum, Meloidogyne incognita and R. solani, causal disease complex of beetroot (Beta Vulgaris L.) [67]. Nevertheless, most ZnONPs may have accumulated on the seed's exterior surface, with only a few particles moving into the stele and available for biodistribution and bioaccumulation, making seed priming less effective than foliar spray [68]. ZnONPs are believed to interact with pathogens through mechanical enfolding, which could be one of the main mechanisms of ZnONPs toxicity against $R$. solani [69].

\section{Conclusions}

This study used the biological control agent T. harzianum as a stabilizing agent for the green synthesis of biogenic ZnONPs with a relatively small size of 8-23 nm. UV-visible 
spectroscopy, XRD, zeta potential, TEM, SEM and EDX were used to validate the synthesis and structure, as well as to characterize size distribution, zeta potential, morphology and so on. Moreover, their antifungal activity against soil-borne pathogens like R. solani (RS9), Fusarium sp. (F10) and M. phaseolina (M4) were demonstrated in vitro and under greenhouse conditions. Trichogenic-mediated ZnONPs inhibited hyphal development in three cotton seedlings, indicating that they are effective against fungal infections. As a consequence of the aforementioned findings, it may be inferred that some T. harzianum strains produce a variety of proteins and enzymes, obviating the need for chemical reducers and stabilizers. As a result, the biological method for the production of ZnONPs utilizing T. harzianum has been presented in this work. The application of ZnONPs in the form of nanofungicides in agroecosystems has yet to be completely investigated and further study on risk assessment is still needed.

Author Contributions: Conceptualization, K.A.A.-E.; and S.A.Z.; methodology, S.A.Z.; investigation, S.A.Z. and M.M.H.; resources, F.M.A.; writing-original draft preparation, writing-review and editing, A.A.A., S.A.O. and K.A.A.-E.; visualization, S.A.Z. and M.M.H.; supervision, S.A.O. and K.A.A.-E.; funding acquisition, K.A.A.-E. and F.M.A. All authors have read and agreed to the published version of the manuscript.

Funding: This research received no external funding.

Conflicts of Interest: The authors declare no conflict of interest.

\section{References}

1. Kew Royal Botanic Gardens. Cultivation of Cotton in Egypt. (Gossypium barbadense, L.). Bull. Misc. Inf. Kew 1897, 122-123, 102-104.

2. Asran-Amal, A.; Abd-Elsalam, K.A.; Omar, M.R.; Aly, A.A. Antagonistic potential of Trichoderma spp. against Rhizoctonia solani and use of M13 microsatellite-primed PCR to evaluate the antagonist genetic variation. J. Plant Dis. Prot. 2005, 112, 550-561. [CrossRef]

3. Fulton, N.D.; Awaddle, B.; Thomas, J.A. Influence of Planting Date on Fungi Isolated from Diseased Cotton Seedlings. Plant Dis. Rep. 1956, 40, 556-558.

4. Colyer, P.D. Frequency and Pathogenicity of Fusarium spp. Associated with Seedling Diseases of Cotton in Louisiana. Plant Dis. 1988, 72, 400-402. [CrossRef]

5. Mihail, J.D.; Taylor, S.J. Interpreting Variability among Isolates of Macrophominaphaseolina in Pathogenicity, Pycnidium Production and Chlorate Utilization. Can. J. Bot. 1995, 73, 1596-1603. [CrossRef]

6. Srivastava, A.K.; Singh, T.; Jana, T.K.; Arora, D.K. Induced Resistance and Control of Charcoal Rot in Cicer Arietinum (Chickpea) by Pseudomonas fluorescens. Can. J. Bot. 2001, 79, 787-795. [CrossRef]

7. Mihail, J.D. Macrophomina. In Methods for Research on Soil-Borne Phytopathogenic Fungi; Singleton, L.L., Mihail, J.D., Rush, C.M., Eds.; American Phytopathological Society Press: St. Paul, MN, USA, 1992; p. 134.

8. Khan, S.A.; Shahid, S.; Mahmood, T.; Lee, C.-S. Contact Lenses Coated with Hybrid Multifunctional Ternary Nanocoatings (Phytomolecule-Coated ZnO nanoparticles: Gallic Acid: Tobramycin) for the Treatment of Bacterial and Fungal Keratitis. Acta Biomater. 2021, 128, 262-276. [CrossRef]

9. Abd-Elsalam, K.A.; Hashim, A.F.; Alghuthaymi, M.A.; Said-Galiev, E. Nanobiotechnological Strategies for Toxigenic Fungi and Mycotoxin Control. In Food Preservation; Academic Press: Cambridge, MA, USA, 2017; pp. 337-364. [CrossRef]

10. Shobha, B.; Lakshmeesha, T.R.; Ansari, M.A.; Almatroudi, A.; Alzohairy, M.A.; Basavaraju, S.; Alurappa, R.; Niranjana, S.R.; Chowdappa, S. Mycosynthesis of ZnO Nanoparticles Using Trichoderma spp. Isolated from Rhizosphere Soils and Its Synergistic Antibacterial Effect against Xanthomonas oryzae pv. oryzae. J. Fungi 2020, 6, 181. [CrossRef]

11. Yusof, H.M.; Mohamad, R.; Zaidan, U.H.; Rahman, N.A.A. Microbial synthesis of zinc oxide nanoparticles and their potential application as an antimicrobial agent and a feed supplement in animal industry: A review. J. Anim. Sci. Biotechnol. 2019, 10, 1-22. [CrossRef]

12. Ammar, H.A.; Alghazaly, M.S.; Assem, Y.; AbouZeid, A.A. Bioengineering and Optimization of PEGylated Zinc Nanoparticles by Simple Green Method Using Monascus purpureus and Their Powerful antifungal Activity Against the Most Famous Plant Pathogenic Fungi, Causing Food Spoilage. Environ. Nanotechnol. Monit. Manag. 2021, 16, 100543. [CrossRef]

13. Abd-Elsalam, K.A.; Khokhlov, A.R. Eugenol Oil Nanoemulsion: Antifungal Activity against Fusarium oxysporum f. sp. vasinfectum and Phytotoxicity on Cottonseeds. Appl. Nanosci. 2015, 5, 255-265. [CrossRef]

14. Alghuthaymi, M.A.; Almoammar, H.; Rai, M.; Said-Galiev, E.; Abd-Elsalam, K.A. Myconanoparticles: Synthesis and Their Role in Phytopathogens Management. Biotechnol. Biotechnol. Equip. 2015, 29, 221-236. [CrossRef] [PubMed]

15. Sosna-Głębska, A.; Sibiński, M.; Szczecińska, N.; Apostoluk, A. UV-Visible Silicon Detectors with Zinc Oxide Nanoparticles Acting as Wave length Shifters. Mater. Today 2020, 20, 1763. [CrossRef] 
16. Fahimmunisha, B.A.; Ishwarya, R.; AlSalhi, M.S.; Devanesan, S.; Govindarajan, M.; Vaseeharan, B. Green Fabrication, Characterization and Antibacterial Potential of Zinc Oxide Nanoparticles Using Aloe Socotrina Leaf Extract: A Novel Drug Delivery Approach. J. Drug Deliv. Sci. Technol. 2020, 55, 101465. [CrossRef]

17. Lingaraju, K.; Naika, H.R.; Manjunath, K.; Basavaraj, R.B.; Nagabhushana, H.; Nagaraju, G.; Suresh, D. Biogenic Synthesis of Zinc Oxide Nanoparticles Using Rutagraveolens (L.) and Their Antibacterial and Antioxidant Activities. Appl. Nanosci. 2016, 6, 703-710. [CrossRef]

18. Hwa, K.-Y.; Subramani, B. Synthesis of Zinc Oxide Nanoparticles on Graphene-Carbon Nanotube Hybrid for Glucose Biosensor Applications. Biosens. Bioelectron. 2014, 62, 127-133. [CrossRef] [PubMed]

19. Singh, J.; Dutta, T.; Kim, K.H.; Rawat, M.; Samddar, P.; Kumar, P. Green'synthesis of Metals and Their Oxide Nanoparticles: Applications for Environmental Remediation. J. Nanobiotechnol. 2018, 16, 84. [CrossRef]

20. Pokhrel, L.R.; Dubey, B. Evaluation of Developmental Responses of Two Crop Plants Exposed to Silver and Zinc Oxide Nanoparticles. Sci. Total Environ. 2013, 452-453, 321-332. [CrossRef]

21. Sur, D.H.; Mukhopadhyay, M. Role of Zinc Oxide Nanoparticles for Effluent Treatment Using Pseudomonas putida and Pseudomonas aureofaciens. Bioprocess Biosyst. Eng. 2019, 42, 187-198. [CrossRef] [PubMed]

22. Sun, Q.; Li, J.; Le, T. Zinc Oxide Nanoparticle as a Novel Class of Antifungal Agents: Current Advances and Future Perspectives. J. Agric. Food Chem. 2018, 66, 11209-11220. [CrossRef]

23. Kalia, A.; Abd-Elsalam, K.A.; Kuca, K. Zinc-Based Nanomaterials for Diagnosis and Management of Plant Diseases: Ecological Safety and Future Prospects. J. Fungi 2020, 6, 222. [CrossRef]

24. Lahuf, A.A.; Kareem, A.A.; Al-Sweedi, T.M.; Alfarttoosi, H.A. Evaluation the Potential of Indigenous Biocontrol Agent Trichoderma Harzianum and Its Interactive Effect with Nanosized ZnO Particles against the Sunflower Damping-off Pathogen. Rhizoctoniasolani. In Proceedings of the IOP Conference Series: Earth and Environmental Science, Banda Aceh, Indonesia, 21-22 August 2019; IOP Publishing: Bristol, UK, 2019; Volume 365, p. 012033. [CrossRef]

25. Khan, S.A.; Shahid, S.; Lee, C.-S. Green Synthesis of Gold and Silver Nanoparticles Using Leaf Extract of ClerodendrumInerme; Characterization, Antimicrobial and Antioxidant Activities. Biomolecules 2020, 10, 835. [CrossRef]

26. Consolo, V.F.; Torres-Nicolini, A.; Alvarez, V.A. Mycosinthetized Ag, CuO and ZnO Nanoparticles from a Promising Trichoderma harzianum Strain and Their Antifungal Potential against Important Phytopathogens. Sci. Rep. 2020, 10, 20499. [CrossRef] [PubMed]

27. Zhou, C.; Guo, R.; Ji, S.; Fan, H.; Wang, J.; Wang, Y.; Liu, Z. Isolation of Trichoderma from Forestry Model Base and the Antifungal Properties of Isolate TpsT17 toward Fusarium oxysporum. Microbiol. Res. 2020, 231, 126371. [CrossRef]

28. Dou, K.; Gao, J.; Zhang, C.; Yang, H.; Jiang, X.; Li, J.; Li, Y.; Wang, W.; Xian, H.; Li, S.; et al. Trichoderma biodiversity in major ecological systems of China. J. Microbiol. 2019, 57, 668-675. [CrossRef]

29. Elamawi, R.M.; Al-Harbi, R.E.; Hendi, A.A. Biosynthesis and Characterization of Silver Nanoparticles Using Trichoderma Longibrachiatum and Their Effect on Phytopathogenic Fungi. Egypt. J. Biol. Pest Control 2018, 28, 28. [CrossRef]

30. Rajan, A.; Cherian, E.; Baskar, G. Biosynthesis of zinc oxide nanoparticles using Aspergillus fumigatus JCF and its antibacterial activity. Int. J. Mod. Sci. Technol. 2016, 1, 52-57.

31. Henam, S.D.; Ahmad, F.; Shah, M.A.; Parveen, S.; Wani, A.H. Microwave Synthesis of Nanoparticles and Their Antifungal Activities. Spectrochim. Acta A Mol. Biomol. Spectrosc. 2019, 213, 337-341. [CrossRef] [PubMed]

32. Abd-Elsalam, K.A.; Vasil'kov, A.Y.; Said-Galiev, E.E.; Rubina, M.S.; Khokhlov, A.R.; Naumkin, A.V.; Shtykova, E.V.; Alghuthaymi, M.A. Bimetallic Blends and Chitosan Nanocomposites: Novel Antifungal Agents against Cotton Seedling Damping-Off. Eur. J. Plant Pathol. 2018, 151, 57-72. [CrossRef]

33. Dobrucka, R.; Dlugaszewska, J.; Kaczmarek, M. Cytotoxic and Antimicrobial Effects of Biosynthesized ZnO Nanoparticles Using of Chelidonium majus Extract. Biomed. Microdevices 2018, 20, 5. [CrossRef]

34. Wahab, R.; Ansari, S.G.; Kim, Y.S.; Seo, H.K.; Kim, G.S.; Khang, G.; Shin, H.-S. Low-Temperature Solution Synthesis and Characterization of ZnO Nano-Flowers. Mater. Res. Bull. 2007, 42, 1640-1648. [CrossRef]

35. Wahab, R.; Ansari, S.G.; Kim, Y.S.; Song, M.; Shin, H.-S. The Role of PH Variation on the Growth of Zinc Oxide Nanostructures. Appl. Surf. Sci. 2009, 255, 4891-4896. [CrossRef]

36. Perveen, R.; Shujaat, S.; Qureshi, Z.; Nawaz, S.; Khan, M.I.; Iqbal, M. Green versus Sol-Gel Synthesis of ZnO Nanoparticles and Antimicrobial Activity Evaluation against Panel of Pathogens. J. Mater. Res. Technol. 2020, 9, 7817-7827. [CrossRef]

37. Gao, Y.; Arokia Vijaya Anand, M.; Ramachandran, V.; Karthikkumar, V.; Shalini, V.; Vijayalakshmi, S.; Ernest, D. Biofabrication of Zinc Oxide Nanoparticles from Aspergillus niger, Their Antioxidant, Antimicrobial and Anticancer Activity. J. Clust. Sci. 2019, 30, 937-946. [CrossRef]

38. Jamdagni, P.; Khatri, P.; Rana, J.S. Green Synthesis of Zinc Oxide Nanoparticles Using Flower Extract of Nyctanthes Arbor-Tristis and Their Antifungal Activity. J. King Saud Univ. Sci. 2018, 30, 168-175. [CrossRef]

39. Sadatzadeh, A.; Charati, F.R.; Akbari, R.; Moghaddam, H.H. Green Biosynthesis of Zinc Oxide Nanoparticles via Aqueous Extract of Cottonseed. J. Mater. Environ. Sci. 2018, 9, 2849-2853.

40. Yedurkar, S.; Maurya, C.; Mahanwar, P. Biosynthesis of Zinc Oxide Nanoparticles Using Ixora Coccinea Leaf Extract-A Green Approach. Open J. Synth. Theory Appl. 2016, 5, 1-14. [CrossRef]

41. Malaikozhundan, B.; Vinodhini, J. Nanopesticidal Effects of Pongamiapinnata Leaf Extract Coated Zinc Oxide Nanoparticle against the Pulse Beetle, Callosobruchus maculatus. Mater. Today Commun. 2018, 14, 106-115. [CrossRef] 
42. Soares, V.A.; Xavier, M.J.S.; Rodrigues, E.S.; de Oliveira, C.A.; Farias, P.M.A.; Stingl, A.; Ferreira, N.S.; Silva, M.S. Green Synthesis of ZnO Nanoparticles Using Whey as an Effective Chelating Agent. Mater. Lett. 2020, 259, 126853. [CrossRef]

43. Pandao, M.R.; Sajid, M. Synthesis and Characterization of Nano Zinc Oxide for Linseed. J. Pharmacogn. Phytochem. 2021, 10, 846-848.

44. Baddar, Z.E.; Matocha, C.J.; Unrine, J.M. Surface coating effects on the sorption and dissolution of ZnO nanoparticles in soil. Environ. Sci. Nano 2019, 6, 2495-2507. [CrossRef]

45. Divya, M.; Govindarajan, M.; Karthikeyan, S.; Preetham, E.; Alharbi, N.S.; Kadaikunnan, S.; Khaled, J.M.; Almanaa, T.N.; Vaseeharan, B. Antibiofilm and Anticancer Potential of $\beta$-Glucan-Binding Protein-Encrusted Zinc Oxide Nanoparticles. Microb. Pathog. 2020, 141, 103992. [CrossRef] [PubMed]

46. Zakharova, O.; Kolesnikov, E.; Vishnyakova, E.; Strekalova, N.; Gusev, A. Antibacterial activity of ZnO nanoparticles: Dependence on particle size, dispersion media and storage time. In Proceedings of the IOP Conference Series: Earth Environmental Science, Voronezh, Russia, 4-5 October 2018; IOP Publishing: Bristol, UK, 2019; Volume 226, p. 012062.

47. González, S.C.E.; Bolaina-Lorenzo, E.; Pérez-Trujillo, J.J.; Puente-Urbina, B.A.; Rodríguez-Fernández, O.; Fonseca-García, A.; Betancourt-Galindo, R. Antibacterial and Anticancer Activity of $\mathrm{ZnO}$ with Different Morphologies: A Comparative Study. 3 Biotech 2021, 11, 68. [CrossRef]

48. Pillai, A.M.; Sivasankarapillai, V.S.; Rahdar, A.; Joseph, J.; Sadeghfar, F.; Anuf, A.R.; Rajesh, K.; Kyzas, G.Z. Green Synthesis and Characterization of Zinc Oxide Nanoparticles with Antibacterial and Antifungal Activity. J. Mol. Struct. 2020, $1211,128107$. [CrossRef]

49. Zhao, C.; Zhang, X.; Zheng, Y. Biosynthesis of Polyphenols Functionalized ZnO Nanoparticles: Characterization and Their Effect on Human Pancreatic Cancer Cell Line. J. Photochem. Photobiol. B 2018, 183, 142-146. [CrossRef]

50. Ruddaraju, L.K.; Pammi, S.V.N.; Pallela, P.N.V.K.; Padavala, V.S.; Kolapalli, V.R.M. Antibiotic Potentiation and Anti-Cancer Competence through Bio-Mediated ZnO Nanoparticles. Mater. Sci. Eng. C Mater. Biol. Appl. 2019, 103, 109756. [CrossRef] [PubMed]

51. Javed, R.; Rais, F.; Fatima, H.; Haq, I.U.; Kaleem, M.; Naz, S.S.; Ao, Q. Chitosan Encapsulated ZnO Nanocomposites: Fabrication, Characterization and Functionalization of Bio-Dental Approaches. Mater. Sci. Eng. C Mater. Biol. Appl. 2020, $116,111184$. [CrossRef]

52. Elumalai, K.; Velmurugan, S.; Ravi, S.; Kathiravan, V.; Adaikala Raj, G. Bio-Approach: Plant Mediated Synthesis of ZnO Nanoparticles and Their Catalytic Reduction of Methylene Blue and Antimicrobial Activity. Adv. Powder Technol. 2015, 26, 1639-1651. [CrossRef]

53. Teulon, J.M.; Godon, C.; Chantalat, L.; Moriscot, C.; Cambedouzou, J.; Odorico, M.; Ravaux, J.; Podor, R.; Gerdil, A.; Habert, A.; et al. On the Operational Aspects of Measuring Nanoparticle Sizes. Nanomaterials 2018, 9, 18. [CrossRef]

54. Nain, V.; Kaur, M.; Sandhu, K.S.; Thory, R.; Sinhmar, A. Development, Characterization and Biocompatibility of Zinc Oxide Coupled Starch Nanocomposites from Different Botanical Sources. Int. J. Biol. Macromol. 2020, 162, 24-30. [CrossRef] [PubMed]

55. Rastogi, L.; Arunachalam, J. Sunlight Based Irradiation Strategy for Rapid Green Synthesis of Highly Stable Silver Nanoparticles Using Aqueous Garlic (Allium sativum) Extract and Their Antibacterial Potential. Mater. Chem. Phys. 2011, 129, 558-563. [CrossRef]

56. Gupta, M.; Tomar, R.S.; Kaushik, S.; Mishra, R.K.; Sharma, D. Effective Antimicrobial Activity of GreenZnONano Particles of Catharanthus roseus. Front. Microbiol. 2018, 9, 2030. [CrossRef] [PubMed]

57. He, L.; Liu, Y.; Mustapha, A.; Lin, M. Antifungal Activity of Zinc Oxide Nanoparticles against Botrytis Cinerea and Penicillium expansum. Microbiol. Res. 2011, 166, 207-215. [CrossRef] [PubMed]

58. Yehia, R.S.; Ahmed, O.F. In Vitro Study of the Antifungal Efficacy of Zinc Oxide Nanoparticles against Fusarium oxysporum and Peniciliumexpansum. Afr. J. Microbiol. Res. 2013, 7, 1917-1923. [CrossRef]

59. Barsainya, M.; Pratap Singh, D. Green Synthesis of Zinc Oxide Nanoparticles by Pseudomonas aeruginosa and Their Broad-Spectrum Antimicrobial Effects. J. Pure Appl. Microbiol. 2018, 12, 2123-2134. [CrossRef]

60. Shen, Z.; Chen, Z.; Hou, Z.; Li, T.; Lu, X. Ecotoxicological Effect of Zinc Oxide Nanoparticles on Soil Microorganisms. Front. Environ. Sci. Eng. 2015, 9, 912-918. [CrossRef]

61. Raghupathi, K.R.; Koodali, R.T.; Manna, A.C. Size-Dependent Bacterial Growth Inhibition and Mechanism of Antibacterial Activity of Zinc Oxide Nanoparticles. Langmuir 2011, 27, 4020-4028. [CrossRef]

62. Hulkoti, N.I.; Taranath, T.C. Biosynthesis of Nanoparticles Using Microbes-A Review. Colloids Surf. B Biointerfaces 2014, 121, 474-483. [CrossRef] [PubMed]

63. Farouk, A.M. Improvement of Bean Resistance to Damping-Off and Root-Rot Diseases. Ph.D. Thesis, Cairo University, Cairo, Egypt, 2016.

64. Boruah, S.; Dutta, P. Fungus Mediated Biogenic Synthesis and Characterization of Chitosan Nanoparticles and Its Combine Effect with Trichoderma asperellum against Fusarium oxysporum, Sclerotium rolfsii and Rhizoctonia solani. Indian Phytopathol. 2021, 74, 81-93. [CrossRef]

65. Al-Dhabaan, F.A.; Shoala, T.; Ali, A.A.; Alaa, M.; Abd-Elsalam, K.; Abd-Elsalam, K. Chemically-Produced Copper, Zinc Nanoparticles and Chitosan-Bimetallic Nanocomposites and Their Antifungal Activity against Three Phytopathogenic Fungi. Int. J. Agric. Technol. 2017, 13, 753-769. 
66. González-Merino, A.M.; Hernández-Juárez, A.; Betancourt-Galindo, R.; Ochoa-Fuentes, Y.M.; Valdez-Aguilar, L.A.; LimónCorona, M.L. Antifungal Activity of Zinc Oxide Nanoparticles in Fusarium oxysporum-Solanum lycopersicum Pathosystem under Controlled Conditions. J. Phytopathol. 2021, 169, 533-544. [CrossRef]

67. Khan, M.R.; Siddiqui, Z.A. Role of Zinc Oxide Nanoparticles in the Management of Disease Complex of Beetroot (Beta vulgaris L.) Caused by Pectobacterium betavasculorum, Meloidogyne incognita and Rhizoctonia solani. Hortic. Environ. Biotechnol. 2021, 62, 225-241. [CrossRef]

68. Khan, M.; Siddiqui, Z.A. Zinc Oxide Nanoparticles for the Management of Ralstoniasolanacearum, Phomopsis Vexans and Meloidogyne Incognita Incited Disease Complex of Eggplant. Indian Phytopathol. 2018, 71, 355-364. [CrossRef]

69. Khan, M.; Khan, A.U.; Alam, J.; Parveen, A.; Moon, I.-S.; Alam, M.; Cabral-Pinto, M.M.; Ahamed, M.; Yadav, V.K.; Yadav, K. Molecular Docking of Biosynthesized Zinc Oxide Nanoparticles to Screen Their Impact on Fungal Pathogen of Carrot Plant. Res. Sq. 2021. [CrossRef] 